\title{
Experimental investigation of a one-sided ejector nozzle
}

\author{
K.B.M.Q. Zaman ${ }^{1}$, A.F. Fagan ${ }^{2}$ and J.E. Bridges ${ }^{3}$ \\ NASA Glenn Research Center \\ Cleveland, $\mathrm{OH} 44135$
}

\begin{abstract}
A fundamental exploratory experiment is conducted assessing the performance of a onesided ejector with the eventual goal of noise reduction for jet engines. The hardware is comprised of an 8:1 rectangular nozzle together with an ejector box whose lower surface is flush with the lower lip of the nozzle. Secondary flow is allowed through a gap between the upper lip of the nozzle and a flap that constitutes the upper surface of the ejector. Wall static pressures and Pitot probe surveys are conducted to evaluate the performance of the ejector with variation of geometric parameters. It is found that addition of vortex generating tabs at the upper lip of the nozzle significantly increases secondary flow entrainment. The entrainment is further enhanced by a divergence of the ejector upper surface. Limited noise measurements are done. The baseline ejector (without tabs) often encounters flow resonance with accompanying tones. The tabs have the additional benefit of eliminating those tones in all cases. However, for the tabbed case, addition of the ejector produces insignificant further noise reduction. This is due to the fact that the flow remains unmixed on the lower half of the ejector. The focus of ongoing and future efforts is to achieve sufficient mixing of the flow so that the exhaust velocities are uniformly low, while keeping the ejector hardware short and lightweight.
\end{abstract}

\section{Introduction}

An ejector is a device that involves a shroud around a jet nozzle in which secondary or ambient fluid is entrained by the primary jet. The net mass flow rate at the exit of the ejector is increased and the corresponding velocity is decreased relative to the primary jet alone. Turbulent mixing at the interface of the primary and secondary streams facilitates the entrainment and therefore the efficiency of the device depends on the mixing process which in turn depends on geometrical as

\footnotetext{
${ }^{1}$ Inlets \& Nozzles Branch, AIAA Associate Fellow.

${ }^{2}$ Acoustics Branch, AIAA Associate Fellow.

${ }^{3}$ Optics \& Photonics Branch, AIAA Associate Fellow.
} 
well as flow parameters. Use of vortex generators or lobed mixers at the primary nozzle lip can significantly enhance the entrainment process and the resultant pumping of secondary flow. Configurations involving such mixers have been typically referred to as 'mixer ejector nozzles'.

There have been numerous previous studies on ejectors as fluidic pumps and as a device for thrust augmentation. The vast literature on the subject may be appreciated from the fact that Ref. [1], published in 1967, cited 585 prior publications, dating as far back as 1919. Much of the earlier work focused on analysis of ejector performance. Thrust augmentation and its application in Vertical/Short Takeoff and Landing (V/STOL) aircraft was addressed in many papers, (e.g., [2-4] and several prior works cited in [1]). Later publications continued to address ejector flow and performance theoretically as well as experimentally, e.g., [5-9]. Other investigations addressed applications of the ejector and methods for improving its performance, e.g., [10-13]. The list of citations given herein is far from complete and an interested reader may look up the bibliographies of the listed ones for other past work.

While the phenomenon of thrust augmentation by ejectors is attractive and applies to cases like V/STOL engines, where high lift is desired during takeoff and landing, in many flight applications it is not feasible. This is because with forward flight thrust augmentation diminishes due to increased ram drag. Reference [7] finds that thrust augmentation decreases with increasing flight Mach number and becomes zero at a flight Mach number of about 0.7. On the other hand, the ejector principle has been used successfully in a variety of applications, especially for mass flow augmentation. For example, it has been utilized for powering the 'free-jet' co-flow in a large-scale jet noise measurement facility at NASA Glenn Research Center (GRC), [14].

Ejectors also hold significant potential for jet noise reduction. This aspect of ejectors has also been addressed in many previous studies over several decades, e.g., [15-22]. The noise reduction potential stems from the fact that jet noise roughly scales as the eighth power of the exhaust velocity. A decrease in exhaust velocity by using an ejector would thus yield significant reduction in jet noise. As an example, assume that the velocity is reduced to $70 \%$ of the primary jet velocity with an ejector shroud that has an exit diameter 1.464 times the primary nozzle diameter (assuming 50\% entrainment and uniform flow at the ejector exit, to satisfy continuity). Then from the principle $I \sim U_{j}^{8} D^{2}$ (where, $I$ is noise intensity, $U_{j}$ the jet exhaust velocity and $D$ the ejector exit diameter, and assuming fixed observer distance), about $9 \mathrm{~dB}$ reduction in $I$ may be achievable. The benefit would increase rapidly with decreasing exhaust velocity. In fact, a reduction in exhaust velocity by mixing 
fan flow with the primary flow is also the basis for noise reduction achieved with high bypass ratio engines in modern subsonic aircraft.

For noise reduction, the ejector principle was adopted in the design of a supersonic aircraft considered in a past NASA/Industry program (High Speed Civil Transport, HSCT program, conducted during the 1990's). By using an ejector with lobed-mixers, parametric variations yielded exhaust velocities that were less than $60 \%$ of the primary jet velocity, [21]. For example, with primary-to-ejector area ratio of 2.8, exhaust velocities were reduced from about $2400 \mathrm{ft} / \mathrm{s}$ to about 1400 $\mathrm{ft} / \mathrm{s}$. This yielded a reduction in noise intensities by about $15 \mathrm{~dB}$, as measured at various polar locations (and roughly following the simple scaling law discussed in the previous paragraph). The resultant noise, in effective perceived noise level (EPNL) metric, satisfied strict airport noise regulation standards [21]. (FAR36 stage III levels were satisfied with margin; an interested reader may look up [23] for the definitions of noise standards.) Unfortunately, the HSCT program was canceled in late 1990's due to other NASA priorities.

The ejector nozzle in the HSCT program turned out to be quite large and heavy. This is a limitation with the ejector design. Even though much work has been done to improve mixer-ejector nozzle performance [19-22], there is a need for further research to achieve more efficient mixing of the streams so that the hardware can be kept short and lightweight. The present fundamental study is prompted with that goal and with certain aircraft concepts in mind as explained in the following.

The study is initiated to explore the feasibility of a one-sided ejector that may be applicable to aircraft concepts with an over-the-wing engine configuration. These concepts often involve an 'aft deck' for shielding some exhaust noise from reaching an observer on the ground. If the engine exhaust is rectangular, it could be a relatively simple task of deploying flaps over the exhaust and on the sides to create the one-sided ejector configuration. When not needed those flaps can be stowed away. As stated before, the ultimate goal is to achieve jet noise reduction while keeping the hardware simple and lightweight. With these notions the present fundamental exploratory study is undertaken with relatively simple hardware. An 8:1 aspect ratio rectangular nozzle is chosen for the primary jet flow. A suitable ejector box, described shortly, is attached at the exit of the nozzle. Surveys are made with the primary focus on ejector pumping characteristics. Limited data are obtained so far on comparative noise radiation characteristics. This paper provides a status report of the effort. 


\section{Experimental Facility}

The experiments are conducted in an open jet facility at NASA GRC. An image of the jet rig with the ejector configuration is shown in Fig. 1(a). Figure 1(b) is a close-up view of the nozzle with the ejector apparatus, and a schematic is shown in Fig. 1(c). The rectangular nozzle is of 8:1 aspect ratio ('NA8Z', described in previous publications, e.g., Ref. 24 that also describes the jet facility). It has exit dimensions of 5.34"x0.66", thus, an equivalent diameter, $D=2.12^{\prime \prime}$. All dimensions are quoted in inches. The lower plate of the ejector box is placed flush with the lower lip (longer dimension) of the nozzle. The upper plate ('ejector flap') is moveable and a scaled drawing with the pressure tap locations is shown in Fig. 1(d). The side plates have slots (Fig. 1b) allowing placement of the upper plate at different heights, $H$, as well as different inclination angles. The angle $\alpha$ of the upper plate is defined with respect to the axial direction, such that a positive $\alpha$ denotes the divergent condition. The adjustment of $H$ as well as $\alpha$ is facilitated by sets of 'plugs' (Fig. 1b) that are made using 3-D printing. The upper plate rests on the four plugs (two on each of the two side plates) and is secured by screws. The plugs fill the slots on the side walls so that there is no leakage.

The shape of the leading edge (LE) of the upper plate can be seen in Fig. 1(d). It is chosen arbitrarily; however, a CFD study on the effect of the leading edge radius showed this shape to be close to optimum for ejector pumping. Details of the companion CFD study are to be presented in a separate paper at the same conference [25]. There are five static pressure ports on the upper plate, spaced axially at mid-span. These are located at axial distances of $0.6^{\prime \prime}, 1.00 ", 1.34 ", 1.76^{\prime \prime}$ and 2.32" from the LE (Fig. 1d). In the experiments, static pressure $\left(P_{s}\right)$ for all five ports is recorded as a function of the primary jet Mach number $M_{j}$, for a given set of parameters. A higher value of the suction pressure (i.e., negative $P_{s}$ ) denotes higher entrainment by the ejector. The Mach number $M_{j}$ is defined simply based of the plenum pressure, $p_{0}$, and the ambient pressure, $p_{a}$, (regardless of the static pressure changes at the exit of the nozzle caused by the ejector). It is given by, $M_{j}=\left(\left(\left(p_{0} / p_{a}\right)^{(\gamma-1) / \gamma}-1\right) \frac{2}{\gamma-1}\right)^{1 / 2}$, where $\gamma(=1.4)$ is the ratio of specific heats for air.

A three-sensor Pitot probe rake is used to carry out Mach number surveys at the exit of the ejector. These data are integrated to obtain the total mass flow rate through the ejector $\left(m_{E}\right)$. The primary mass flow rate $\left(m_{I}\right)$ is measured by an orificemeter in the supply line. Sound pressure level (SPL) spectra data are obtained using microphones held fixed on an overhead arm. Unless stated otherwise 
the data presented are for the polar location of $\theta=90^{\circ}$. The test chamber is semi-anechoic [24]. Even though the plenum face and nearby surfaces are wrapped with sound absorbing material during noise measurements, the noise spectral amplitudes are qualitative. However, they are deemed sufficient for assessing the comparative effects on the noise levels as the parameters are varied.

Data are obtained with and without 'mixing tabs' ('chevrons') attached to the upper lip of the primary nozzle (Fig. 1e). The baseline (no-tab primary nozzle and the ejector) flow is noisy and often emits tones. Tabs eliminate the tones and improve ejector pumping, as will be seen from the results in the following. The tab strip is machined out of 0.014" thick sheet metal. Each of the triangular tabs has $0.416^{\prime \prime}$ base and $0.315^{\prime \prime}$ height. There are 11 full and two half tabs at the ends. The tabs penetrate the primary flow at approximately a $20^{\circ}$ angle. The tab strip was attached to the upper surface of the nozzle with epoxy and two screws (Fig. 1e).

\section{Results}

Static pressure $\left(P_{s}\right)$ data as a function of jet Mach number $M_{j}$ are presented in Figs. 2-6. In Fig. 2, data are shown for the effect of variation of ejector height $H$ (Fig. 1c). There are three sets of data for three values of $H$; the data on the left column (Figs. 2a-c) represent baseline case without tabs while the data on the right column (Figs. 2d-f) is for the tab case. Note that the ordinate scale is negative and spans 0 to -4 psig. The ejector creates a vacuum and the 'suction pressure' increases with increasing $M_{j}$. The most remarkable observation is that the tabs cause a large increase in the suction pressure for a given $H$. For each value of $H$, the increase is threefold or more over most of the $M_{j}$ range covered. The tabs cause increased mixing, more ambient air is entrained, resulting in higher suction pressures. The increased entrainment is demonstrated by Pitot probe survey results shown in the following.

For the tab case, data for a few other values of $H$ are shown in Fig. 3. It is observed that the suction pressure is high at small values of $H$ but becomes smaller with increasing $H$. The suction is marginal at the highest value of $H$ covered (1.83"). Obviously, for very large $H$ the flow would become a free jet and the measured (gauge) pressure would tend to be zero. Cross-plots of the data for the tab case are shown in Fig. 4. The pressure variation with $M_{j}$ at each of the five ports is captured in these plots. Note that port 1 is the closest to the leading edge; the port locations are given in the Experimental Facility section (Fig. 1d). One finds that the suction pressures are the highest near the leading edge but gradually drop off with increasing downstream distance. At the last port location 
the data indicate a sudden jump across the transonic regime $\left(M_{j} \approx 1\right)$. This is thought to be due to the passage of a shock whose location for a given configuration depends on $M_{j}$.

The divergence angle of the upper plate is also found to have a large impact on the suction pressure. This is shown in Fig. 5 with data for six values of $\alpha\left(-1^{\circ}, 1^{\circ}, 2^{\circ}, 3^{\circ}, 4^{\circ}\right.$ and $\left.6^{\circ}\right)$. These data are for the tab cases. Different sets of plugs were used while the gap at the entrance $(G$, Fig. 1c) was approximately held constant. Actual values of $G$ and $H$ are indicated in each case. Note that corresponding data for $\alpha=0$ are in Fig. 3(f). One finds that the 'peak' suction pressure for the convergent case $\left(\alpha=-1^{\circ}\right)$ is significantly smaller than that for the $\alpha=0$ case. It increases sharply when a divergence is introduced. As $\alpha$ is stepped through $-1^{\circ}, 0^{\circ}$ and $+1^{\circ}$, the peak suction at port 1 attains the approximate values of $-1.5,-3$ and -5 psig, respectively. The maximum peak suction is reached in the $\alpha$ range of $2^{\circ}$ to $4^{\circ}$ (port 1 pressure reaching about -9 psig). At even higher values of $\alpha$ there is a drop-off due to flow separation on the upper wall. The latter becomes clear from the Pitot probe survey data shown shortly.

The suction pressure data for three different lengths of the ejector $(L=L O+\Delta L$, Fig. $1 \mathrm{~b})$ are shown in Fig. 6. As in Fig. 2, the three sets of data are shown without tabs (left column, Figs. 6a-c) and with tabs (right column, Figs. 6d-f). These data are for an ejector height $H=0.902 "$. While these are for $L=4^{\prime \prime}, 5^{\prime \prime}$ and 6", corresponding data for $L=3^{\prime \prime}$ can be found in Fig. 2(e). It is clear that for each $L$, tabs account for a large increase in the suction pressure. For either no-tab or tab cases, the ejector length makes only marginal increases in the suction pressure. From $L=3$ " (Fig. 2) to $L=4$ " (Fig. 6) there is some increase in the suction pressure. However, further increases in $L$ do not affect the amplitudes significantly.

So, the main finding so far is that the tabs cause a large increase in the suction pressure. A further significant increase is obtained with a small divergence of the upper plate. An increase in suction pressure implies increased pumping and this is evaluated in the following. First, the impact on the noise field is briefly discussed using Figs. 7-10.

Figure 7 compares the sound pressure level (SPL) spectra with and without tabs for 6 different values of $H$. Pairs of traces are shown in each figure where a blue curve represents the no-tab case and a red curve represents the tab case. It is apparent that in the no-tab case the ejector often yields vigorous resonant tones. The addition of tabs not only eliminates the tones but also brings down the broadband energy levels. In Fig. 8, data for a convergent case $\left(\alpha=-3^{\circ}\right)$ as well as a divergent case $\left(\alpha=+3^{\circ}\right)$ are shown with and without tabs. In both cases the flow without tabs emits tones. 
The tabs again effectively suppress the tones and reduce broadband levels. It should be cautioned that the dramatic reduction of broadband energy seen in these figures does not necessarily imply a large jet noise reduction potential. With the tones there is 'broadband noise amplification'; the tabs take out the tones and along with it the broadband amplitudes drop to levels that would occur had there been no tones. Finally, similar data for four different $L$ are shown in Fig. 9. Without tabs the tones occur at lower values of $L$ (for the given $H=0.902^{\prime \prime}$ ) but with increasing $L$ they disappear. However, it is noted that even though there are no tones for the longer no-tab cases $\left(L=5^{\prime \prime}\right.$ and $\left.6^{\prime \prime}\right)$, the tabs have reduced the low frequency energy substantially.

In Fig. 10, the spectral data are shown for three cases: the free jet from the nozzle without the ejector or tabs (red curve), free jet from the nozzle fitted with the tabs (blue curve), and for the ejector configuration with the tabbed primary nozzle having $H=0.902 "$ (green curve). These data, shown for two polar locations, cover a wider frequency range and are also plotted in log scale in order to allow an easy examination of the effects on both the low and high frequency ends of the spectrum. Addition of the tabs to the nozzle is observed to cause an increase in high frequency energy; however, there is a perceptible reduction in low frequency energy (compare red and green curves). Addition of the ejector has made little further difference, except a small reduction in the high frequency levels (compare green and blue curves). Once again, note that these spectral data are qualitative but nonetheless the result is rather discouraging. The reason for the lack of noise reduction with the present ejector configuration becomes clear with the exit velocity surveys as discussed next.

Pitot probe survey results are shown as Mach number contours in Figs. 11-13. These data are obtained at the exit of the ejector. In Fig. 11, the effect of ejector height $H$ is shown, without and with the tabs. For the no tab case (on left), a boundary layer separation around the middle of the upper surface can be noticed with increasing $H$. The separated zone becomes prominent at $H=1.05$ " and the flow is completely separated at $H=1.33^{\prime \prime}$. With the tabs (on right) the flow is completely attached on the upper surface at $H=1.05^{\prime \prime}$ and only partially separated at $H=1.33^{\prime \prime}$. These results are commensurate with the higher suction pressures measured with the tab cases.

Similar comments can be made about the effect of upper plate divergence from the data shown in Fig. 12; all cases here are with tabs. For $\alpha=2^{\circ}$, the flow is completely attached on the upper surface. At $\alpha=4^{\circ}$ some flow separation has taken place while at $\alpha=6^{\circ}$ there is extensive flow separation. These results explain why the suction pressure attains a maximum value in the $\alpha$ range 
of $2^{\circ}$ to $4^{\circ}$ (Fig. 5). Data for the effect of ejector length with and without tabs are presented in Fig. 13, in a similar manner as in Fig. 11. In the no-tab cases (left), increased length may have reduced flow separation on the upper surface to some extent. With the tabs (right), increased length $L$ allows more mixing to take place. This manifests in a smoothing of the footprints of the tabs. The flow in this case is attached on the upper surface for all values of $L$.

Mass flow rate results obtained from integration of the Mach number data are presented in Fig. 14-16. Data corresponding to the contours shown in Fig. 11 ( $H$ effect) are presented in Fig. 14. Tabs clearly result in an increased mass flow rate at all values of $H$. For the tab cases, a maximum mass flow rate is reached at a height of about 1.33". In the limit of very large $H$, there should not be any ejector effect and the mass flow rate should become close to the value noted for small $H$. This is reflected in the results for the tab case in Fig. 14, the flow rate value drops for $H>1.33^{\prime \prime}$. The effect of varying $L$ and $\alpha$ are shown in Fig. 15. With varying $\alpha$, the maximum flow rate is attained around $4^{\circ}$ while it drops at even higher $\alpha$ due to flow separation. Note that the sets of data in Figs. 14 and 15 were taken at different times, in some cases after reinstalling the tab strip. Also, the data for varying $L$ had to be taken somewhat downstream from the ejector exit due to hardware constraints. This should explain some differences in the flow rate values when cross-checked for the same conditions. The trends in each set with variation of respective parameter, however, should be well represented. With varying $L$, there is only marginal change in the mass flow rate.

Finally, the entrainment of ambient air by the ejector is evaluated. Figure 16 shows the data for the tab case and for variation of $H$. The primary jet mass flow rate $\left(m_{I}\right)$ is shown by the top curve. With increasing $H$ a decrease in $m_{I}$ is noted, apparently due to static pressure changes caused by the ejector. Combining these data with the total mass flow rate measured by Pitot survey (Fig. 14) provides the entainment rate $\left(\left(m_{E}-m_{I}\right) / m_{I}\right)$ which is shown by the bottom curve of Fig. 16 . The trend in the entrainment curve is quite similar to that of mass flow rate $\left(m_{E}\right)$ in Fig. 14. This is because $m_{I}$ remains relatively a constant. The maximum entrainment ratio of about $34 \%$ occurs around $H=1.33^{\prime \prime}$.

Going back to the discussion of the noise data in Fig. 10, it can be seen that in all cases of Figs 11-13 there is a layer of high-speed flow on the lower half of the ejector exit plane. The flow in that region has the same velocity as that at the exit of the primary nozzle. Thus, while enhanced mixing has been achieved by the tabs in the upper half of the flow, yielding attached flow with the upper surface, the flow has not mixed in the lower half. Even a small region of 'hot-spot' would de- 
feat the goal of noise reduction through the $I \sim U_{j}^{8} D^{2}$ scaling law. This is why significant noise reduction has not been observed yet (Fig. 10). On-going and future efforts will focus on this, possibly allowing some ambient flow also from underneath together with tabs or other mixing enhancement devices.

\section{Conclusions}

A one-sided ejector configuration is explored in this study. The ultimate goal is to achieve noise reduction for newer aircraft concepts with over-the-wing engines having rectangular exhausts. In this fundamental exploratory study an 8:1 rectangular nozzle is used together with a simple ejector box. The lower surface of the ejector is placed flush with the lower lip of the nozzle while secondary flow is allowed through a gap between the upper lip of the nozzle and the upper flap of the ejector. Wall static pressures, Pitot probe surveys and limited noise measurements are made. These quantities are measured as a function of geometric parameters with and without mixing tabs placed at the nozzle lip. With increasing velocities of the secondary flow at the inlet gap, the static pressure near the leading edge of the flap decreases. Thus, the intensity of this 'suction' pressure should provide a measure of the secondary flow entrainment or ejector pumping efficiency. As the gap width is varied, keeping the upper and lower surfaces of the ejector parallel, pumping efficiency varies. Highest pumping occurs in a range of relatively small gap widths. With increasing gap width the efficiency decreases rapidly when the flow is no longer attached to the upper surface of the ejector. For a given gap, the pumping is found to be enhanced significantly by the introduction of a divergence of the upper surface. Most efficient pumping is achieved for an $\alpha$-range of $2^{\circ}-4^{\circ}$ together with the mixing tabs. The tabs are found to increase the suction pressure often by a factor of 3 . The tab effect occurs due to enhanced mixing between the nozzle flow and the induced secondary flow likely due to introduction of streamwise vortices. The inferences on the pumping efficiencies from the static pressure data are corroborated by Pitot probe surveys at the exit of the ejector.

Limited noise measurements are performed. The baseline ejector configuration often encounters flow resonance with accompanying tones. Use of tabs not only enhances secondary flow entrainment but also eliminates those tones, in all cases tested. However, with the tabbed nozzle the addition of the ejector is found to produce insignificant reduction of the broadband noise. Thus, the jet noise reduction goal has remained elusive. The lack of noise reduction is due to the fact that the flow remains unmixed on the lower half of the ejector. High velocities even on a small region of the 
ejector exit defeat the goal of noise reduction through the $I \sim U_{j}^{8} D^{2}$ scaling law for noise. Future efforts will focus on getting the entire flow mixed so that the exhaust velocities are low uniformly. The emphasis will be on achieving this and the resultant noise reduction while keeping the ejector hardware short and lightweight. An evaluation of thrust loss/augmentation will also be made using additional hardware for the jet facility that is currently under construction.

\section{Acknowledgement}

The work was in support of NASA's Commercial Supersonic Technologies (CST) Project.

\section{References:}

1. Huang, K.P. and Kisielowski, E., "An investigation of the thrust augmentation characteristics of jet ejectors", USAAVLABS Report 67-8, Contract DA-44-177-AMC-322(T), U.S. Army Aviation Materiel Laboratories, Fort Eustis, Virginia, April 1967.

2. Quinn, B., "Compact ejector thrust augmentation", J. Aircraft, vol 10, no. 8, August, 1973.

3. Bevilaqua, P.N., "Evaluation of hypermixing for thrust augmenting ejectors", J. Aircraft, vol. 11, no. 6, p. 348-354, 1974.

4. O’Donnell, R.M. and Squyers, R.A., "V/STOL ejector short diffuser study final report", ATC Report No. B-94300/6CR-26, Prepared for Naval Air Development Center, Warminster, PA, June, 1976.

5. Porter, J.L., Squayers, R.A. and Nagaraja, K.S., “An overview of ejector theory”, AIAA Paper 81-1678, AIAA Aircraft systems and technology conference, Dayton, OH, August 11-13, 1981.

6. Bernal, L.P. and Sarohia, V., "Entrainment and mixing in thrust augmenting ejectors", AIAA Paper 83-0172, $21^{\text {st }}$ Aerospace Sciences Meeting, Reno, NV, Jan. 10-13, 1983.

7. Papamoschou, D., “Analysis of partially mixed supersonic ejector”, J. Prop. \& Power, vol. 12, no. 4, p. 736-741, 1996.

8. Heiser, W.H., "Ejector thrust augmentation", J. Prop. \& Power, vol. 26, no. 6, p. 1325-1329, 2010.

9. Nagaraja, K.S., “Advances in ejector technology - a tribute to Hans von Ohain's vision”, In AFWAL A collection of papers in the Aerospace Sci., p. 499-517, NTIS HC A99/MF A01 CSCL 20D, June 1982. 
10. Throndson, L.W., "Compound ejector thrust augmentor development”, ASME Paper 73-GT-67, ASME Gas Turbine Conf., Washington D.C., April 8-12, 1973.

11. Presz, W.M. Jr., Morin, B.L. and Gousy, R.G., "Forced mixer lobes in ejector designs", J. Propulsion, vol. 4, no. 4, p. 350-355, 1988.

12. Presz, W.M. Jr., Reynolds, G. and McCormick, D., “Thrust augmentation using mixer-ejectordiffuser systems", AIAA Paper 94-0020, 32 ${ }^{\text {nd }}$ Aerospace Sciences Meeting, Reno, NV, January 1013, 1994.

13. Presz, W.M. Jr., Blinn, R.F. and Morin, B.L., "Short efficient ejector systems", AIAA Paper 871837, $23^{\text {rd }}$ Joint Propulsion Conference, San Diego, CA, June 29- July 2, 1987.

14. Long, M.J., "Experimental investigation of an ejector-powered free-jet facility", AIAA Paper 92-3569, $28^{\text {th }}$ Joint Propulsion Conf., Nashville, TN, July 6-8, 1992. (Also NASA TM 105868).

15. Coles, W.D., Mihaloew, J.A. and Callaghan E.E., "Turbojet emgine noise reduction with mixing nozzle-ejector combinations", NACA TN 4317, August, 1958.

16. Seiner, J.M. and Krejsa, E.A., "Supersonic jet noise and High Speed Civil Transport”, AIAA paper 89-2358, 25 ${ }^{\text {th }}$ Joint Propulsion Conference, Monterey, CA, July 10-12, 1989.

17. Lord, W.K., Jones, C.W., Stern A.M., Head, V.L. and Krejsa, E.A., "Mixer ejector nozzle for jet noise suppression", AIAA Paper 90-1909, $26^{\text {th }}$ Joint Propulsion Conference, Orlando, FL, July 16$18,1990$.

18. Presz, W.M. Jr., "Mixer/ejector noise suppressors”, AIAA Paper 91-2243, $27^{\text {th }}$ Joint Propulsion Conference, Sacramento, CA, June 24-26, 1991.

19. DeBonis, J.R., "Full Navier-Stokes analysis of a two-dimensional mixer/ejector nozzle for noise suppression", AIAA Paper 92-3570, 28 th Joint Propulsion Conference, Nashville, TN, July 6-8, 1992.

20. Tillman, T.G. and Presz, W.M. Jr., “Thrust characteristics of a supersonic mixer ejector”, J. Prop. \& Power, vol. 11, no. 5, p. 931-937, 1995.

21. Majjigi, R.K., Balan, C., Mengle, V., Brausch, J.F., Shin, H. and Askew, J.W., "Low noise exhaust nozzle technology development", NASA CR 2005-213325, February, 2005 (originally published as NASA Report HSR044, Nov., 1996).

22. Raman, G. and Taghavi, R., "Aeroacoustic characteristics of a rectangular multi-element supersonic jet mixer-ejector nozzle", J. Sound and Vib., vol. 207, no. 2, p. 227-247, 1997. 
23. Dickson, N., "ICAO Noise standards", International Civil Aviation Organization Symposium on aviation and climate change, "destination green", Montreal, Canada, May 14-16, 2013.

24. Zaman, K.B.M.Q., Fagan, A.F., Bridges, J.E. and Brown, C.A., "An experimental investigation of resonant interaction of a rectangular jet with a flat plate", J. Fluid Mech., vol. 779, pp. 751-775. doi:10.1017/jfm.2015.453, 2015.

25. Hoter, Z., Castner, R.S. and Zaman, K.B.M.Q., "CFD Optimization of Ejector Flaps in a OneSided Mixer Ejector Nozzle", to be presented at the SciTech2019 conference, January 5-9, 2019, San Diego, CA. 

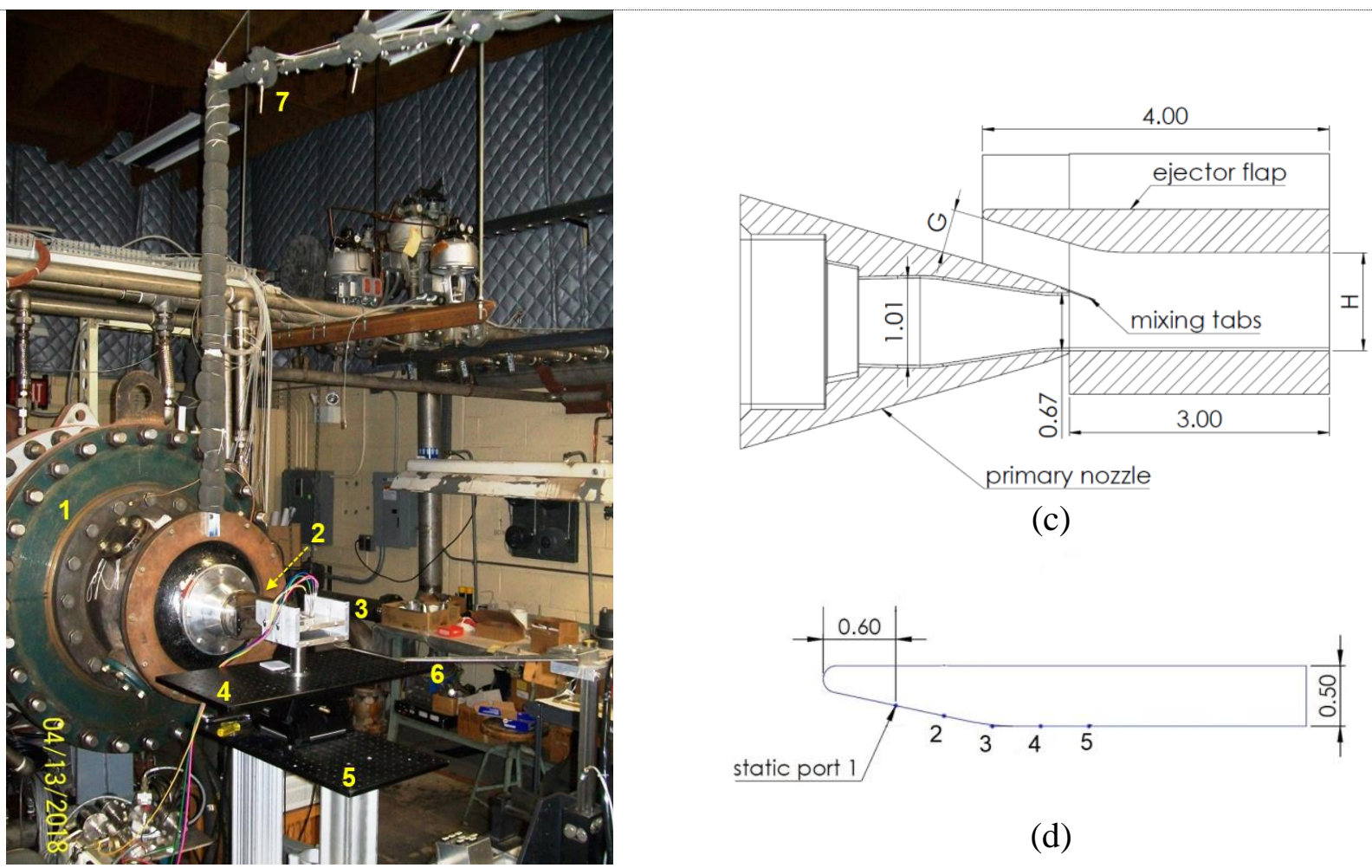

(c)

(a)

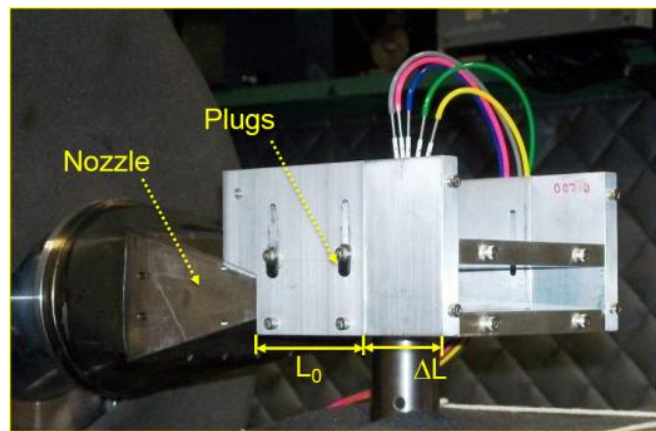

(b)

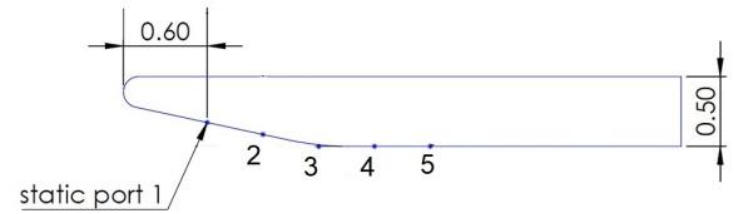

(d)

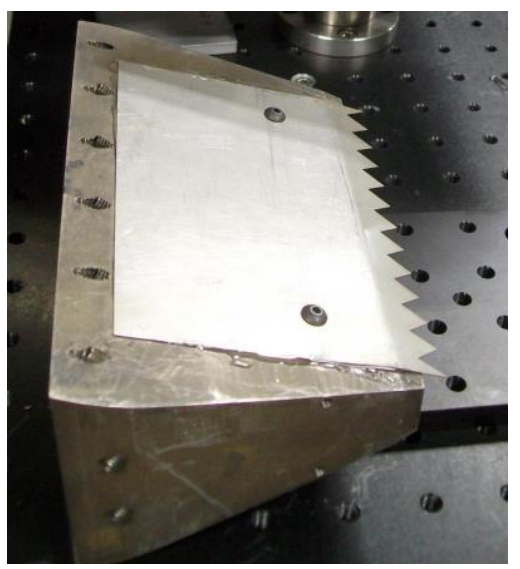

(e)

Figure 1 Experimental facility. (a) Picture of facility showing, 1: plenum chamber, 2: nozzle, 3: ejector module, 4: moveable plate, 5: fixed lower plate, 6: Pitot rake, 7: microphone. (b) Close-up view of ejector. (c) Schematic of nozzle and ejector (dimensions in inches). (d) Schematic of upper plate showing static pressure port locations. (e) Picture of primary nozzle with tab strip attached. 

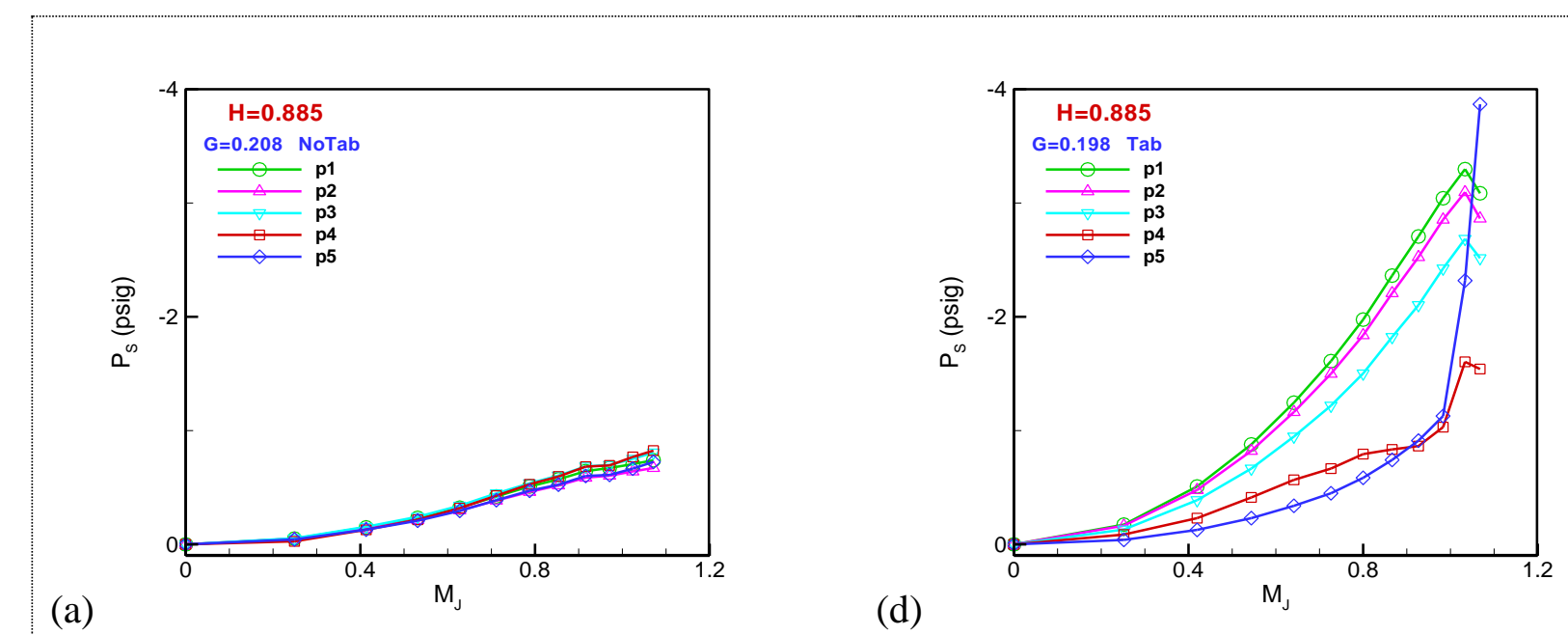

(d)

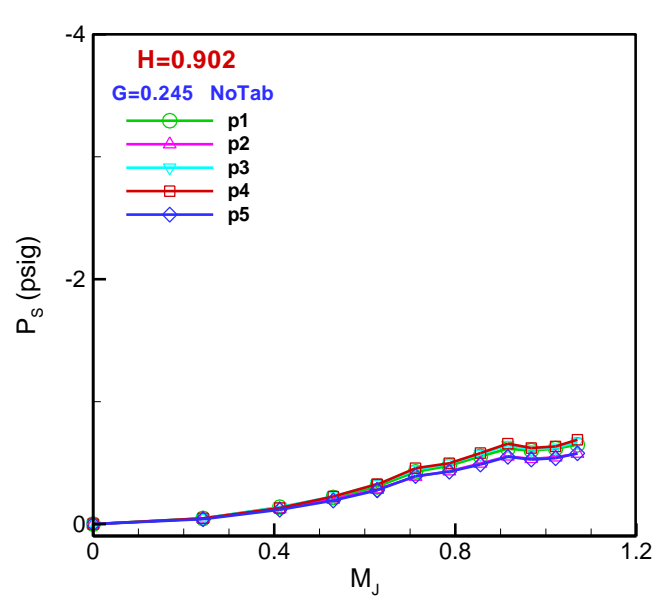

(b)

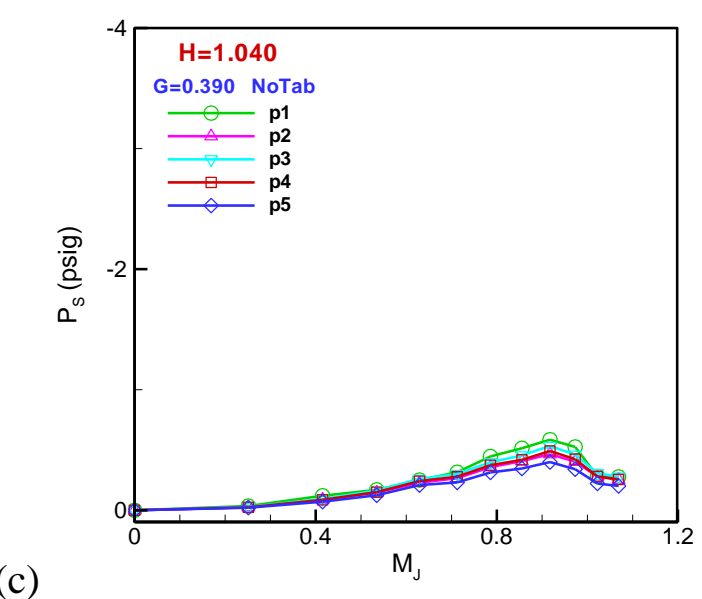

(e)

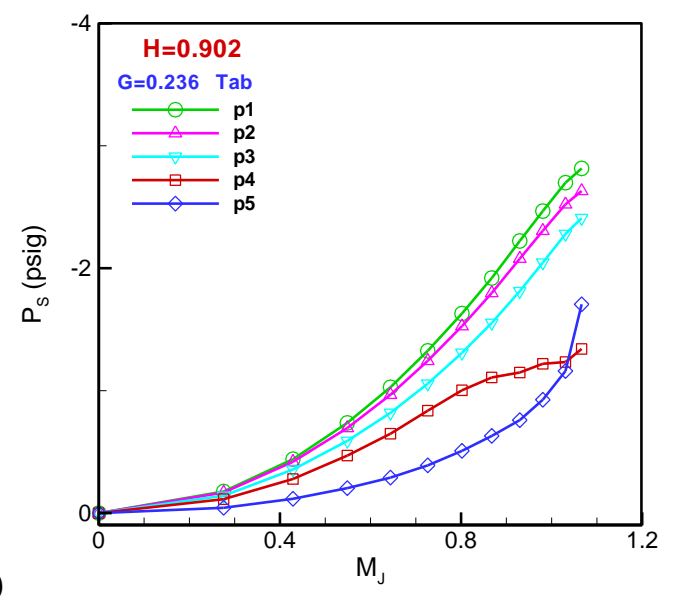

(c)

(f)

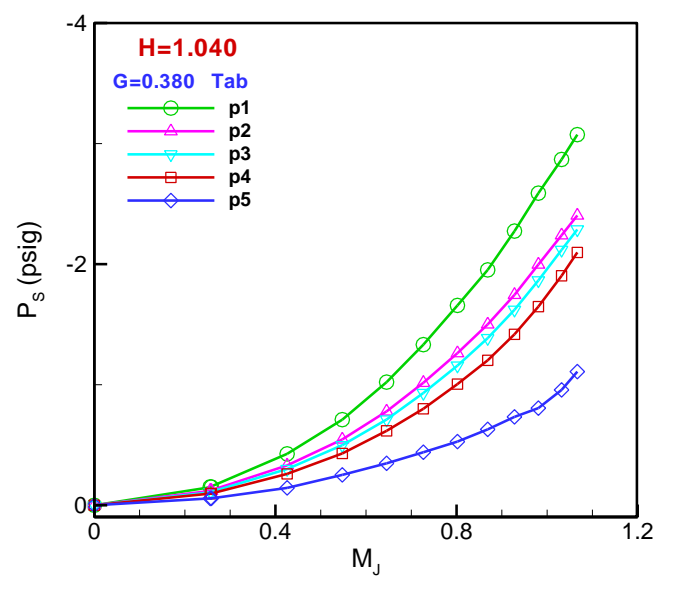

Figure 2 Static pressure versus $M_{j}$ for different upper plate height $H$, as indicated; each graph has data from the five ports. Left column for no-tabs, right column for tabs. 

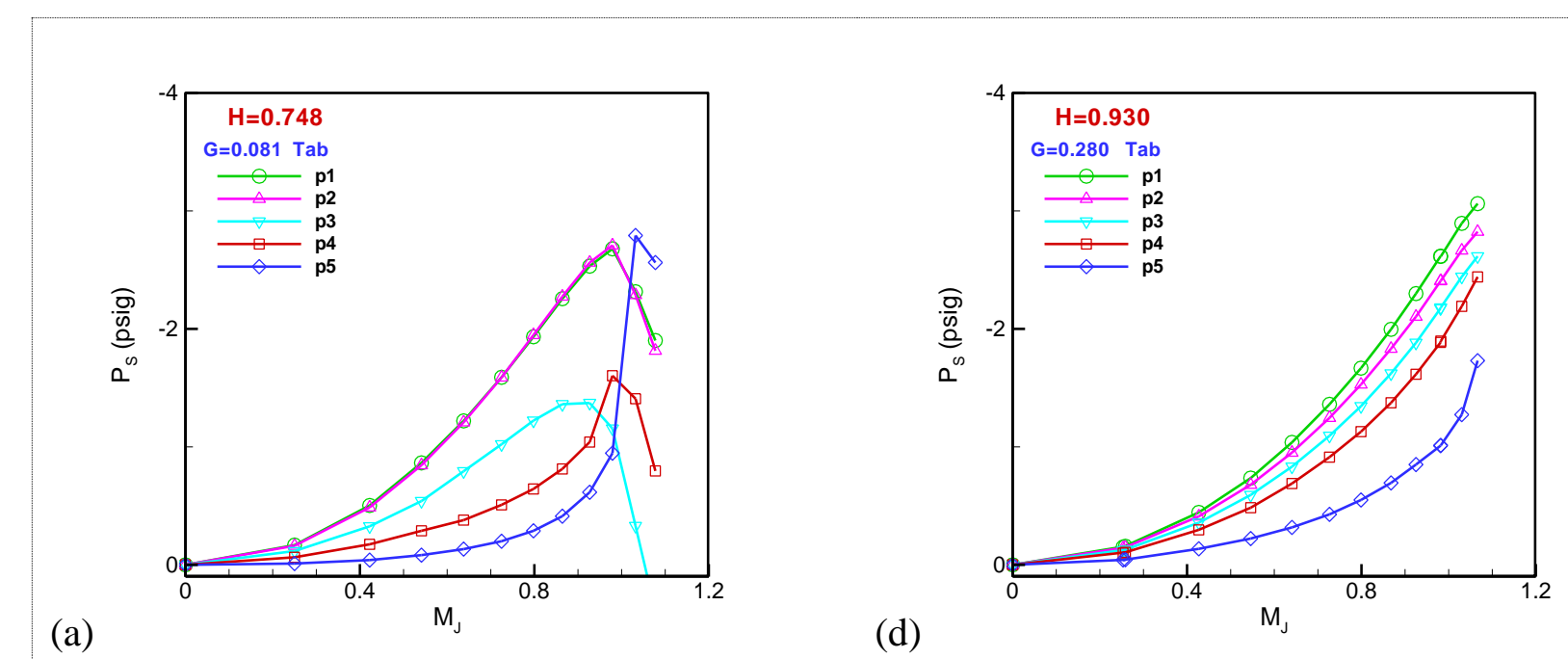

(d)
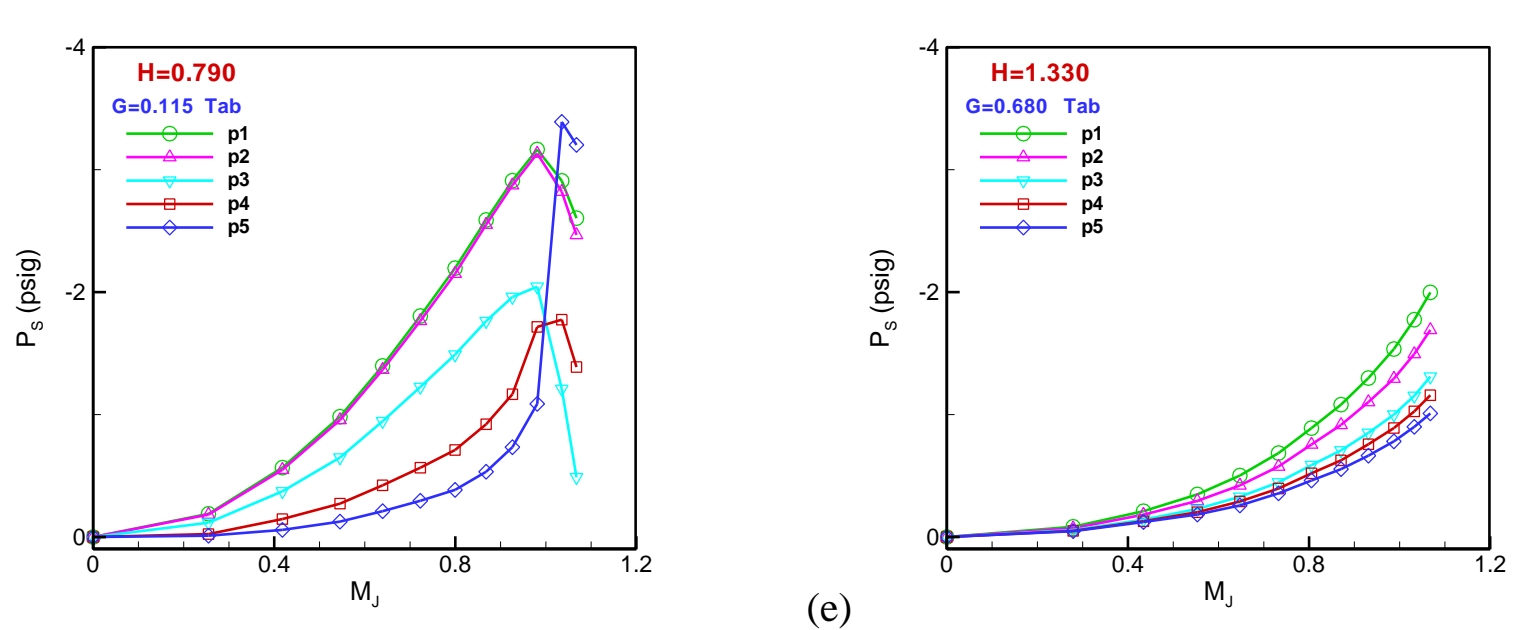

(b)

(e)

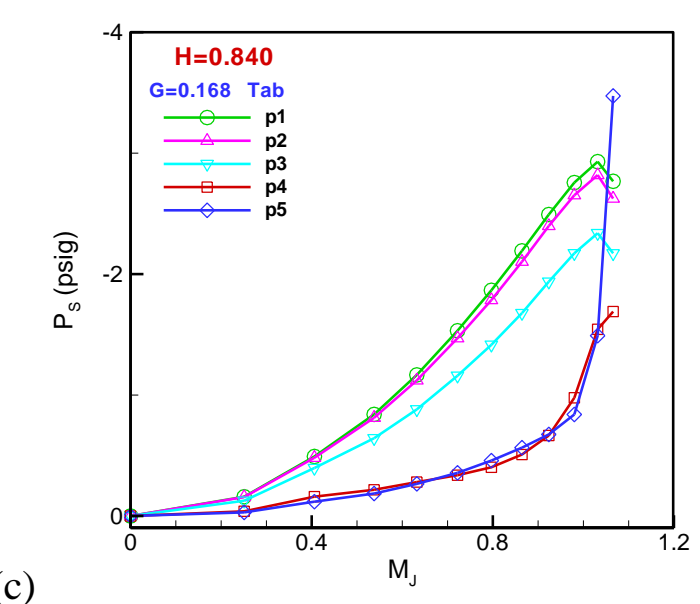

(c)

Figure 3 Static pressure versus $M_{j}$ for the tab case at several other values of $H$.

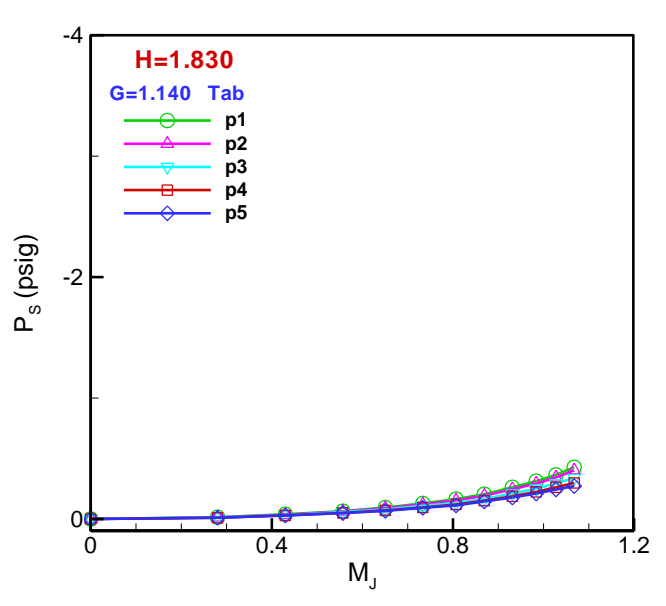

(f) 


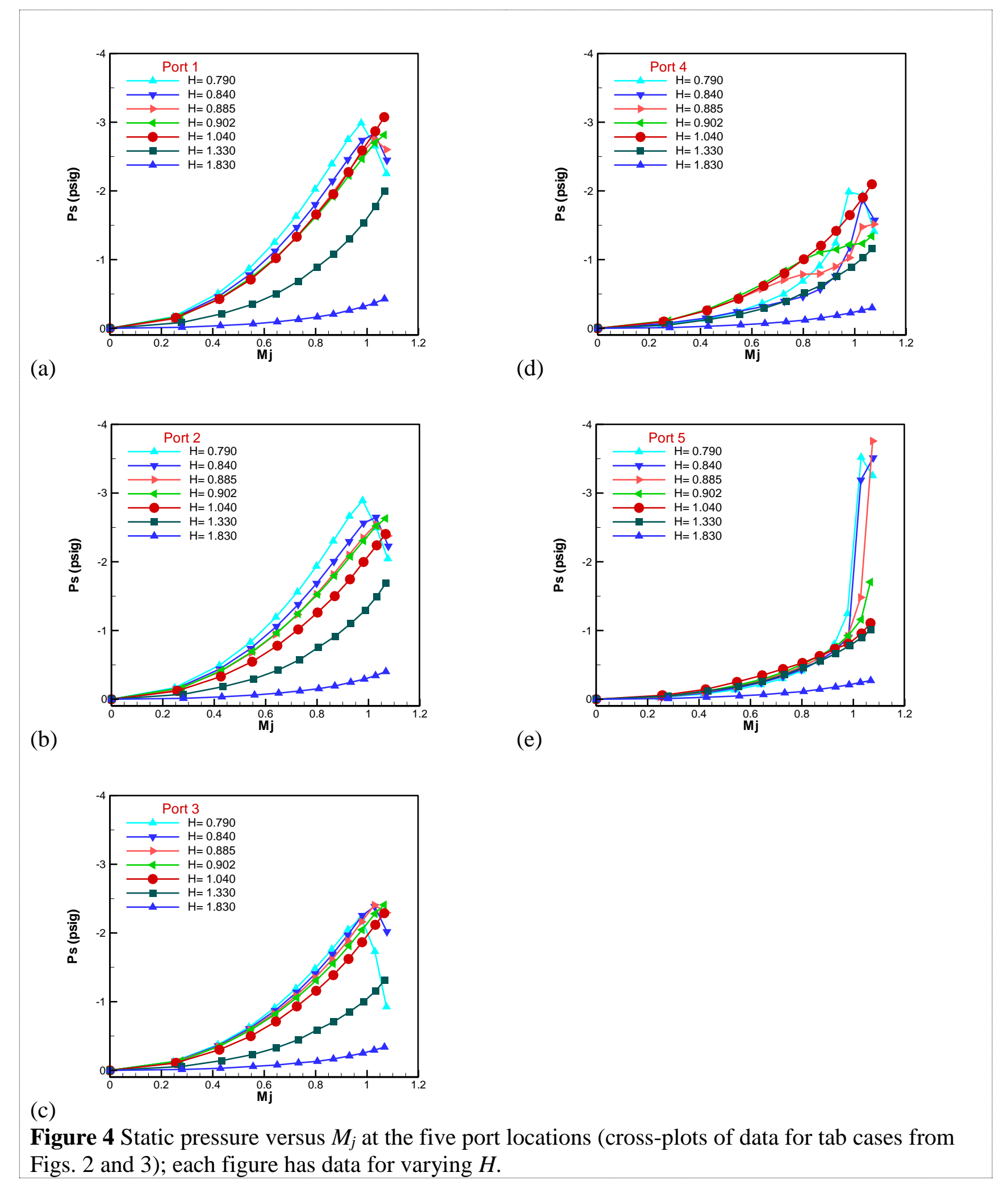




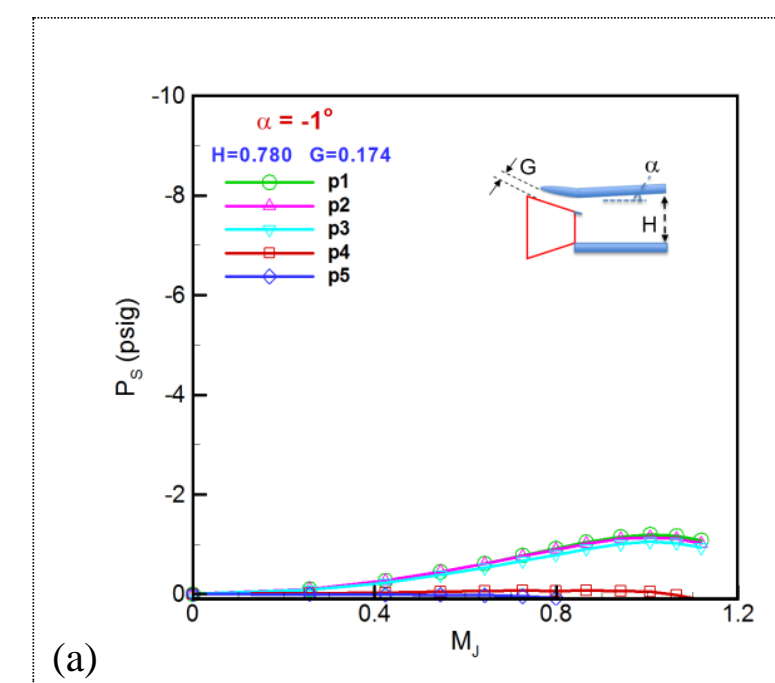

(d)
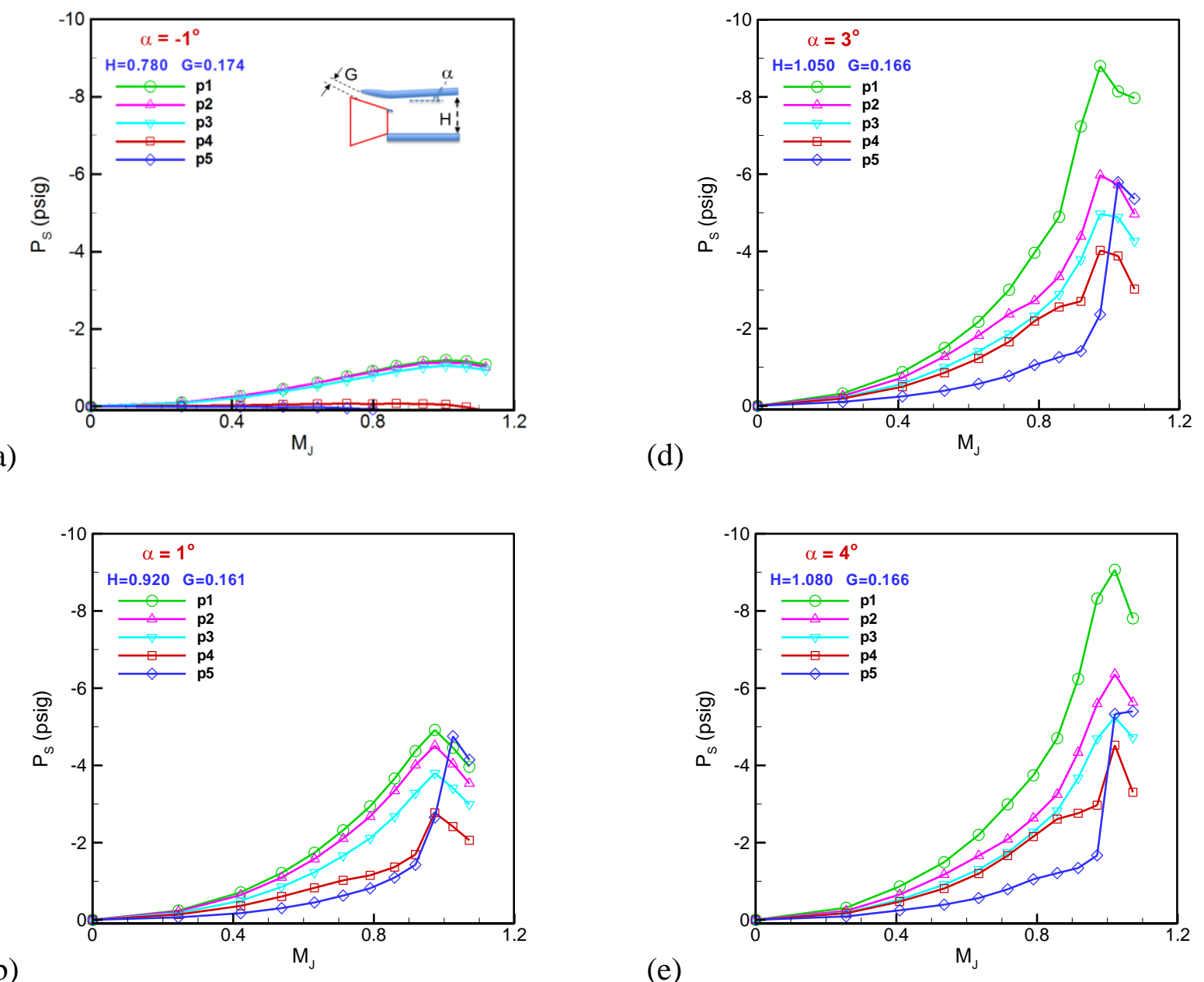

(e)
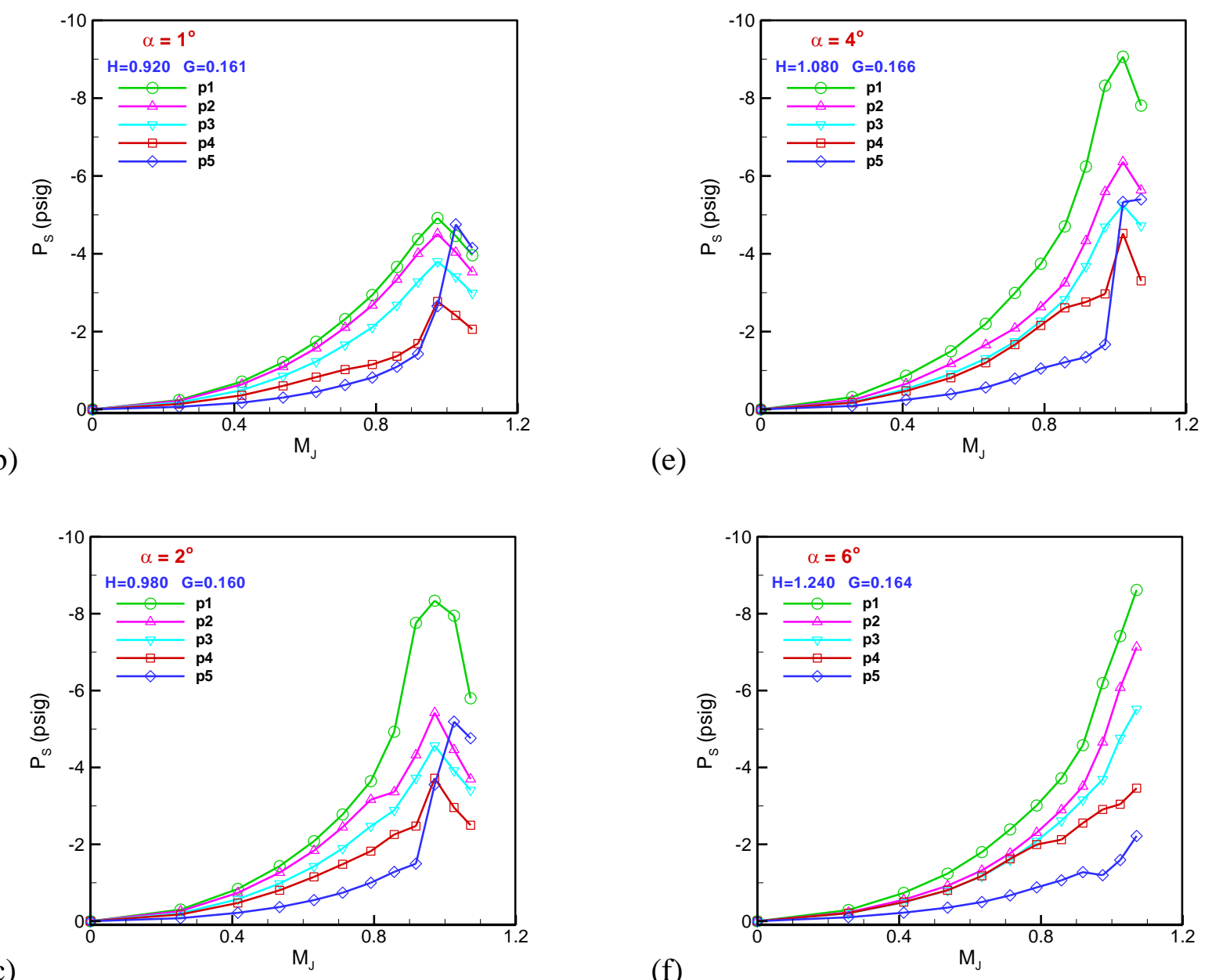

(f)

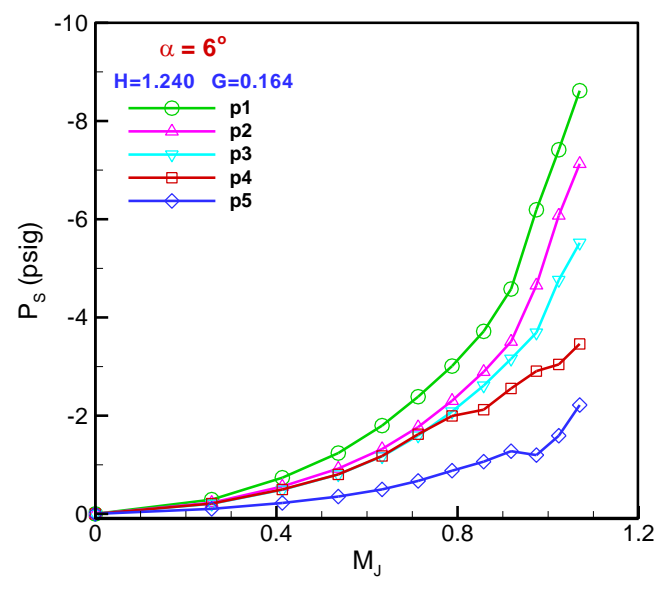

Figure 5 Static pressure versus $M_{j}$ for six divergence angles $(\alpha)$ as indicated (tab cases); the gap $G$ was approximately held the same, actual values are indicated. 


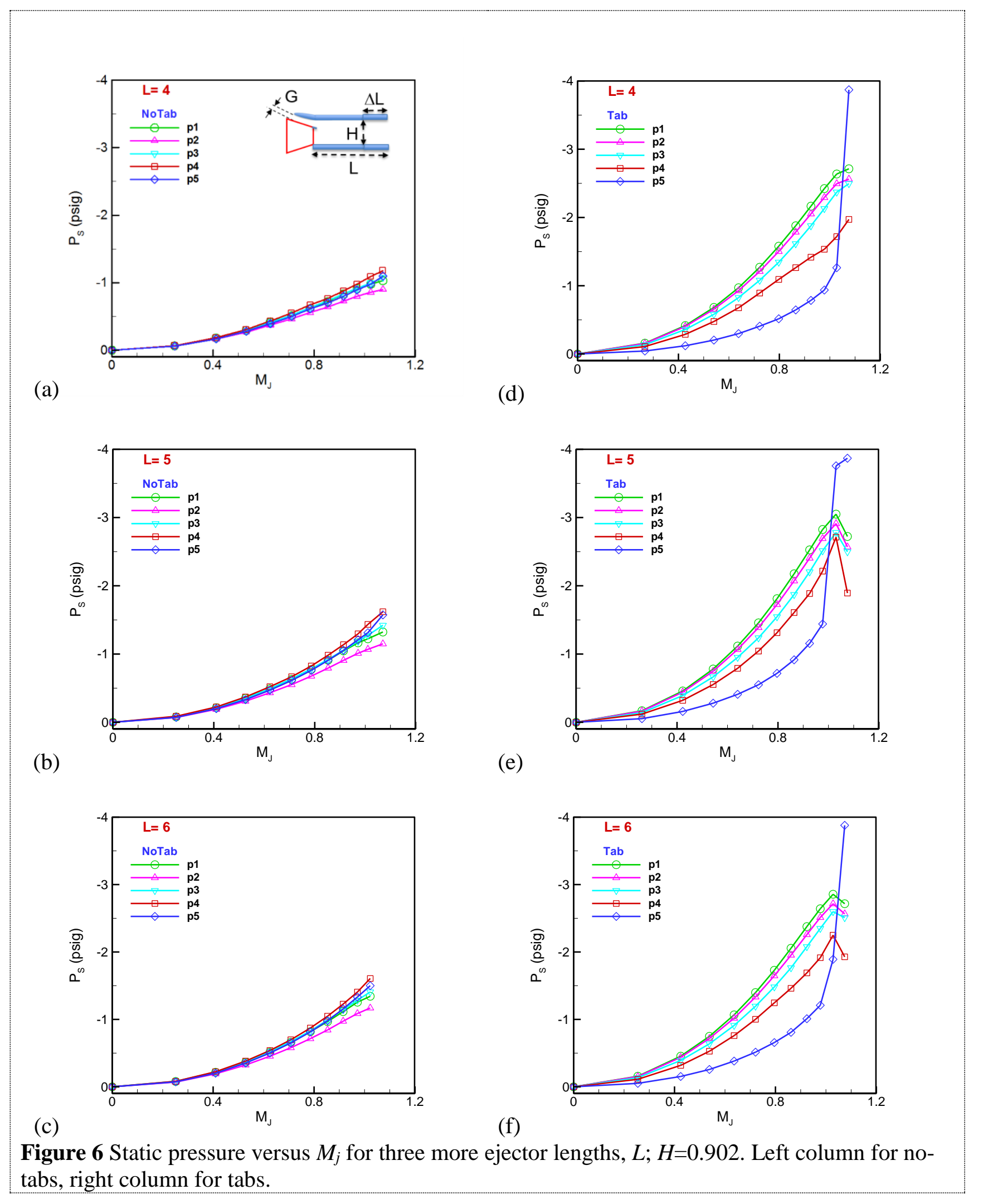




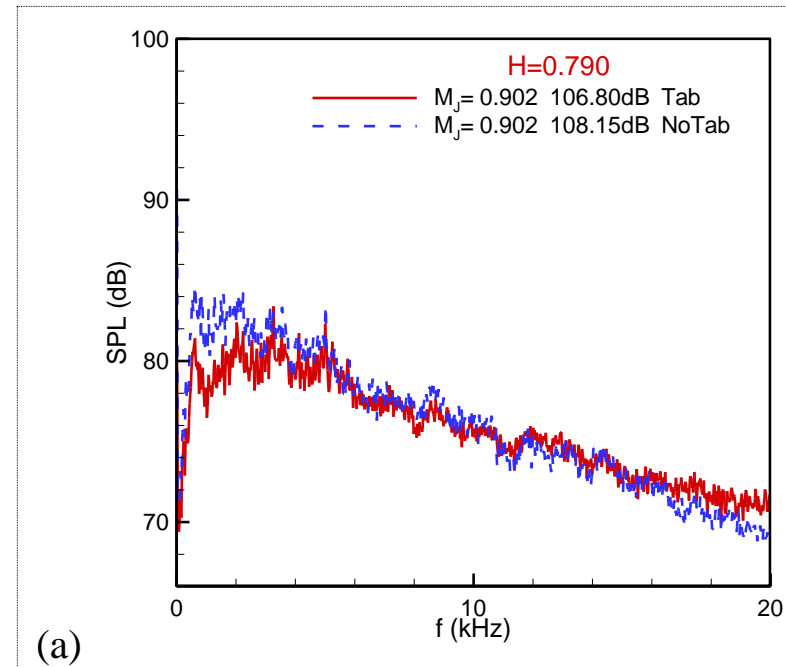

(d)
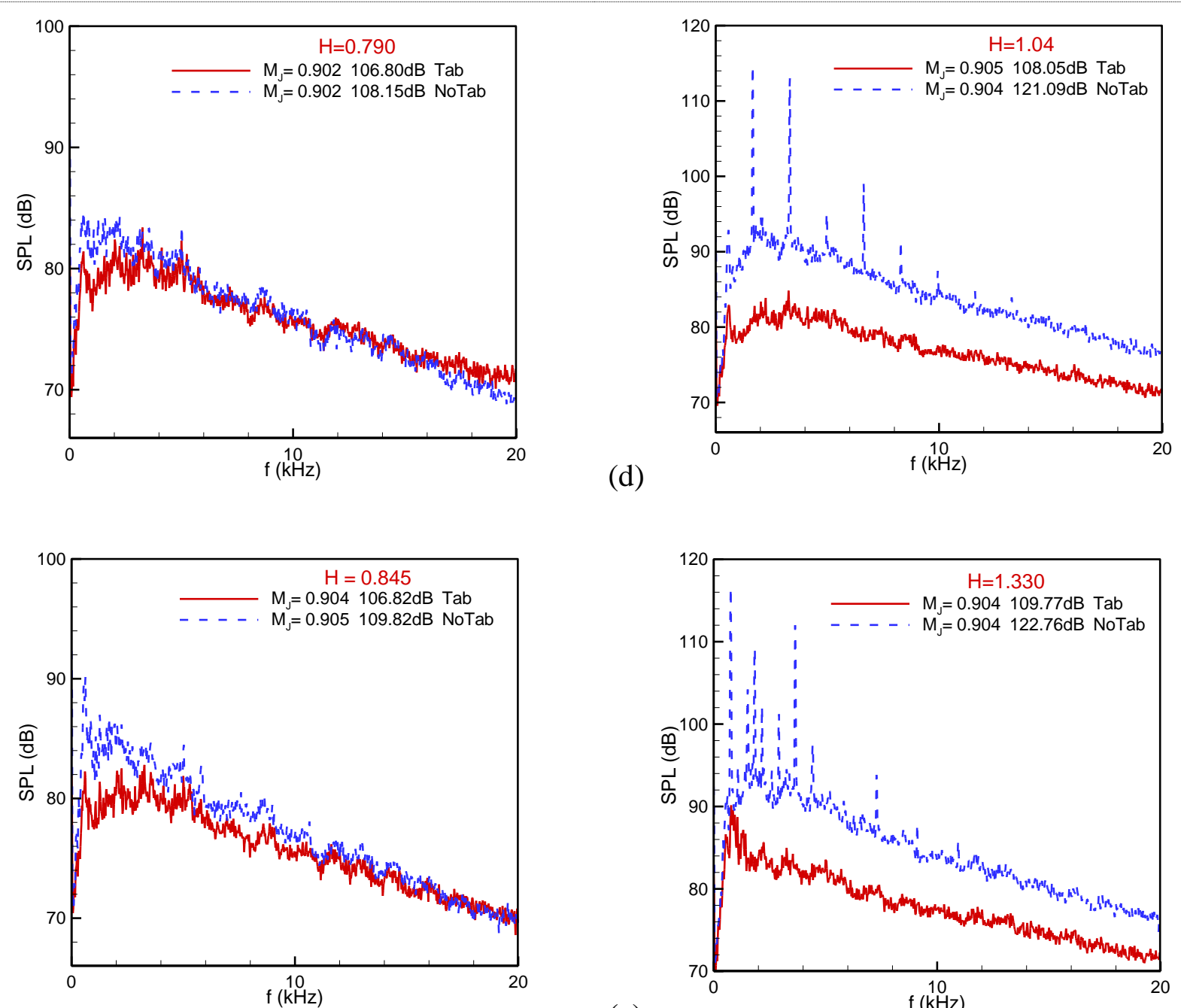

(b)

(e)
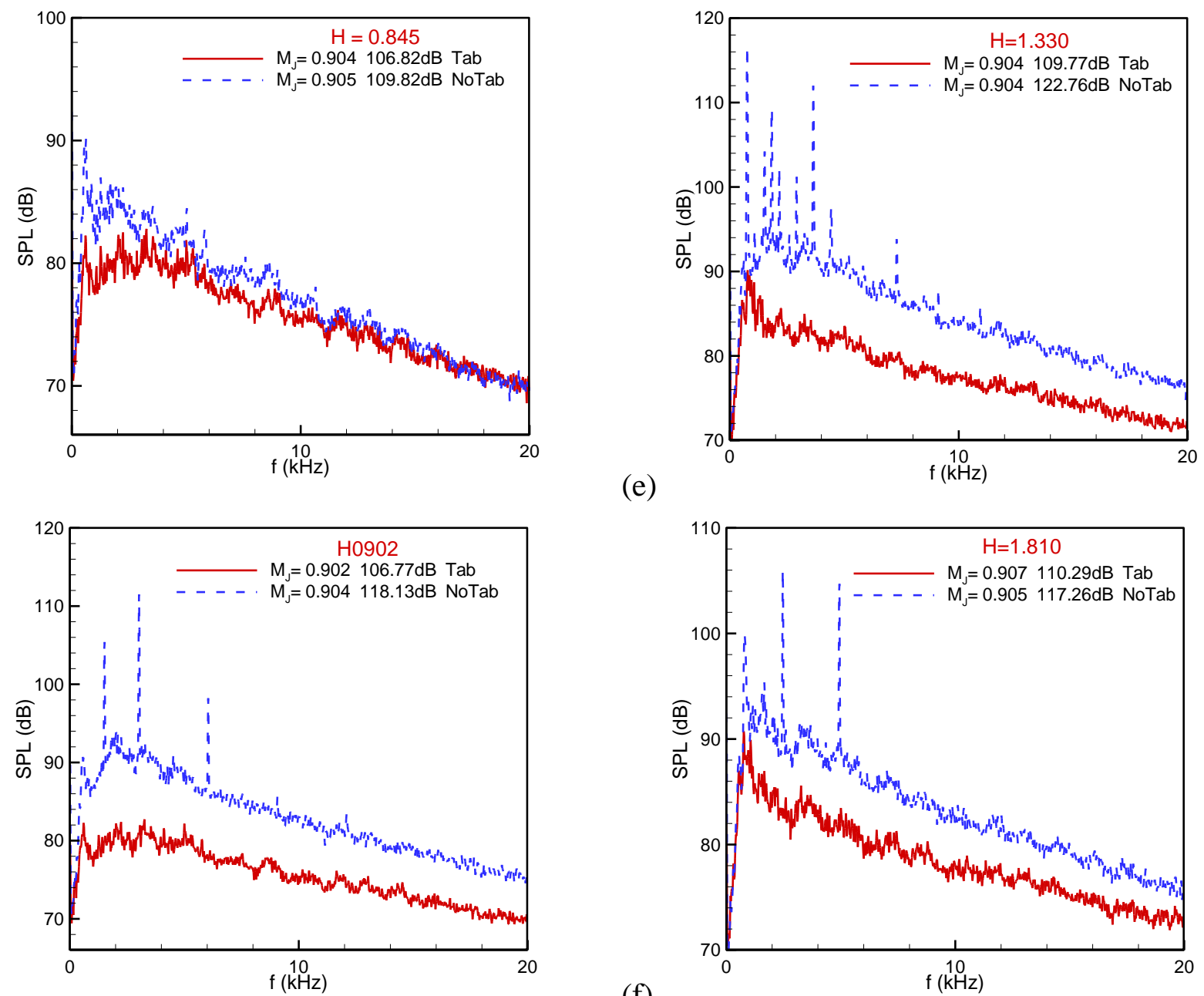

(c)

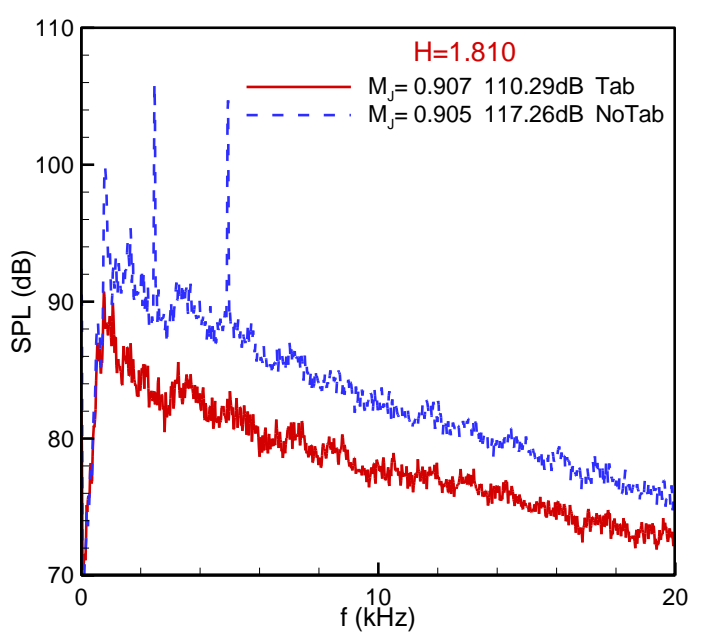

Figure 7 SPL spectra at $M_{j}=0.9$; in each plot blue curve is for no-tab case and red curve is for tab case. The six sets of data are for varying height $H$; second column in legend is OASPL. 


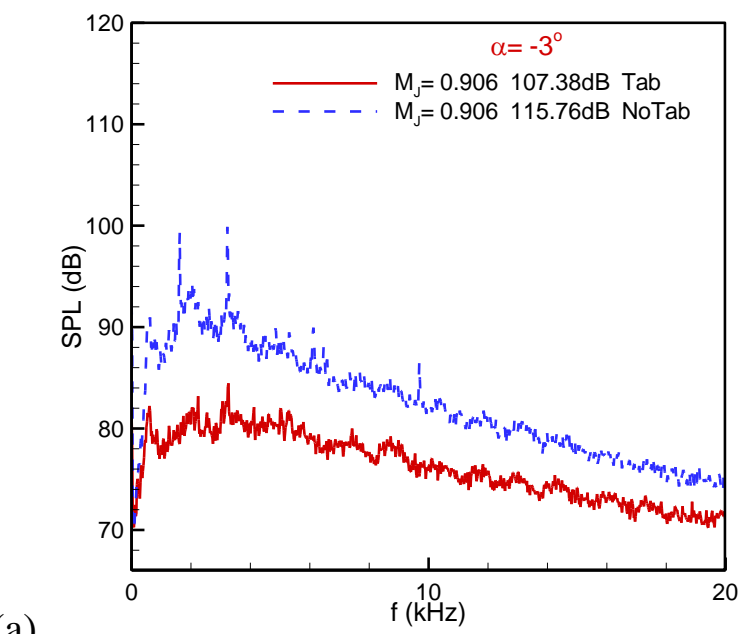

(b)

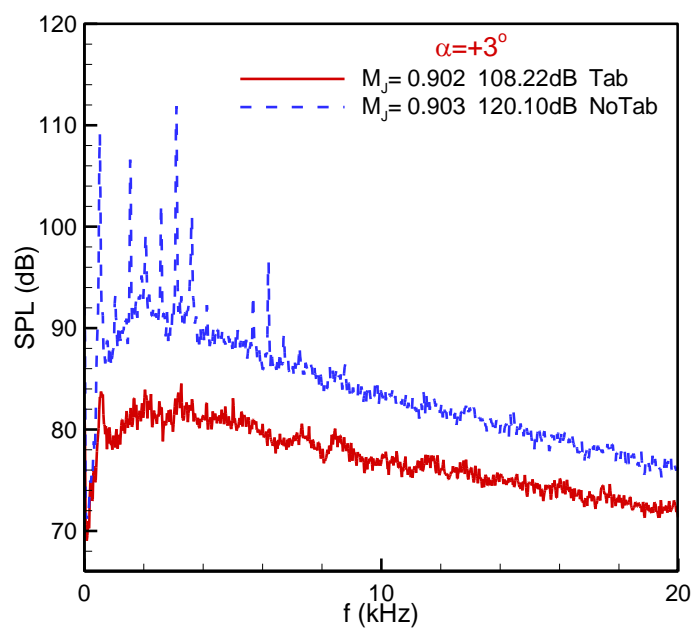

Figure 8 SPL spectra at $M_{j}=0.9$. Data on left for a convergent case ( $\left.\alpha=-3^{\circ}, H=0.883^{\prime \prime}, G=0.375^{\prime \prime}\right)$, on right for a divergent case $\left(\alpha=3^{\circ}, H=1.03^{\prime \prime}, G=0.164^{\prime \prime}\right)$.

(a)
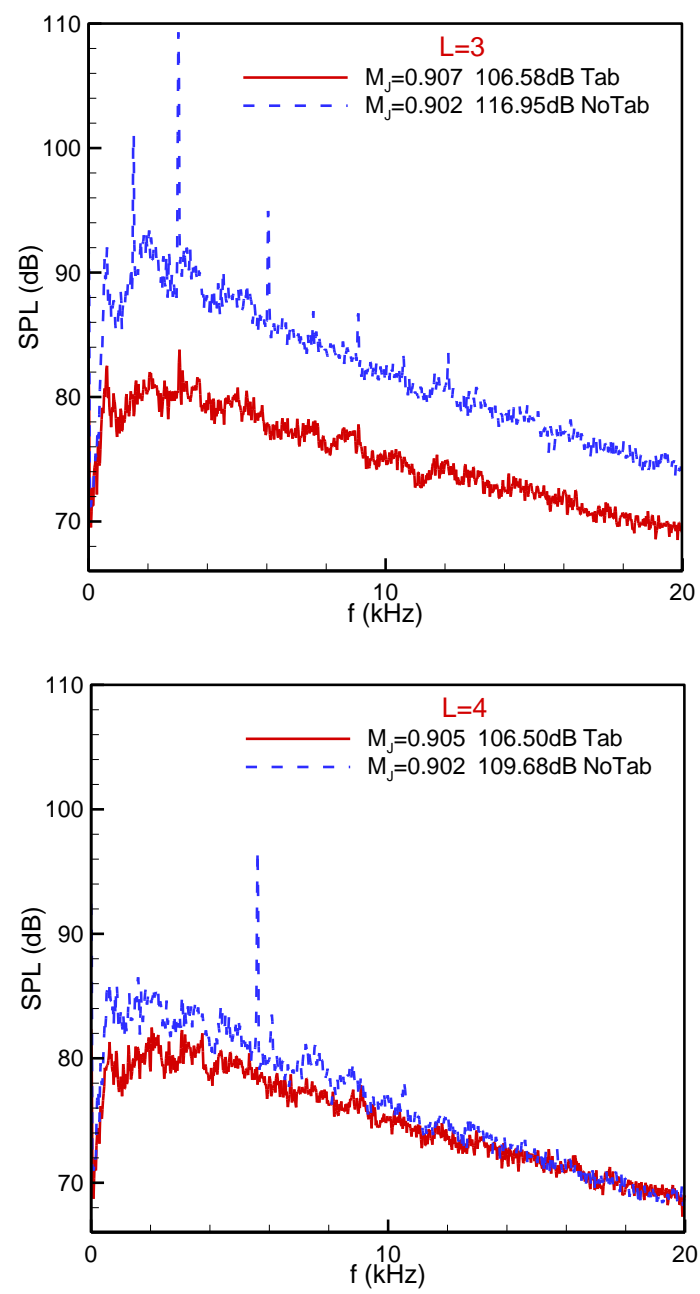

(c)
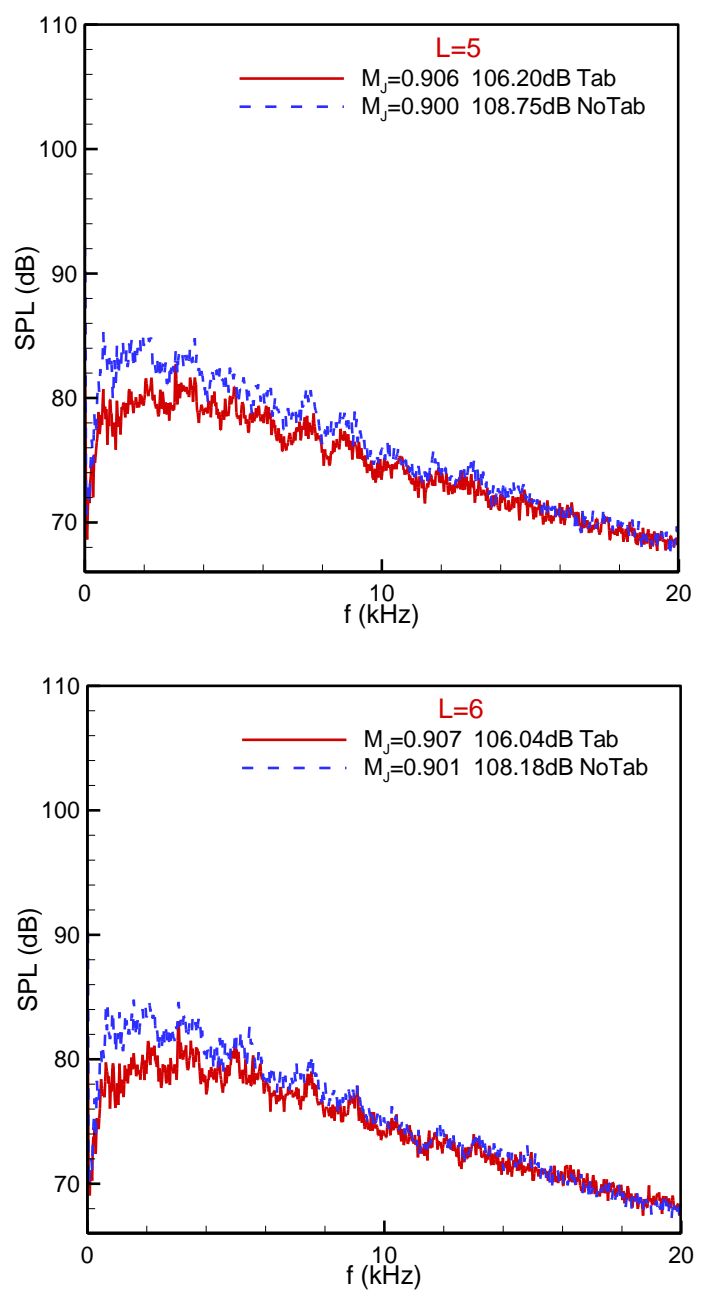

(b)

Figure 9 SPL spectra at $M_{j}=0.9$; in each plot blue curve is for no-tab case and red curve is for tab case. The four sets of data are for varying length $L$; second column in legend is OASPL. 


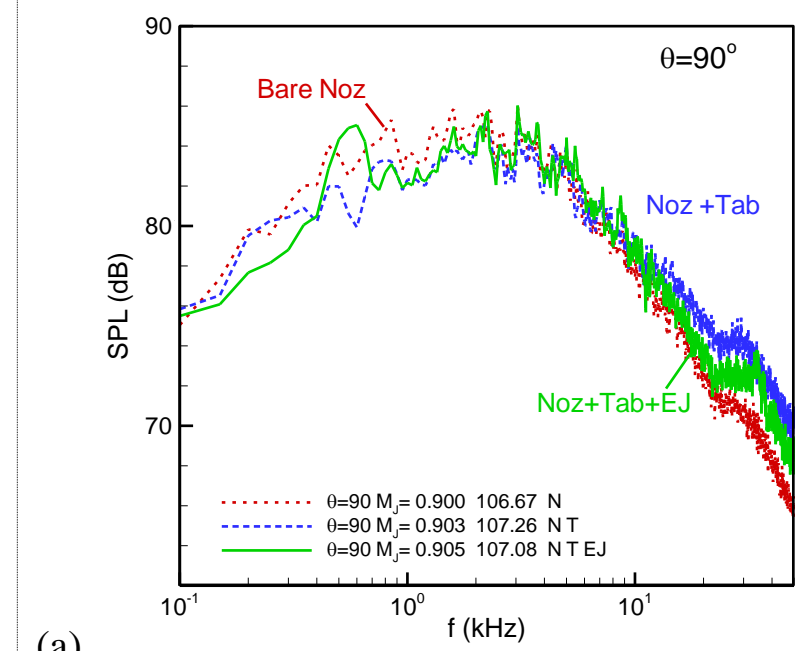

(a)

Figure 10 SPL spectra at $M_{j}=0.9$ at two polar locations as indicated; red: bare nozzle, blue: nozzle

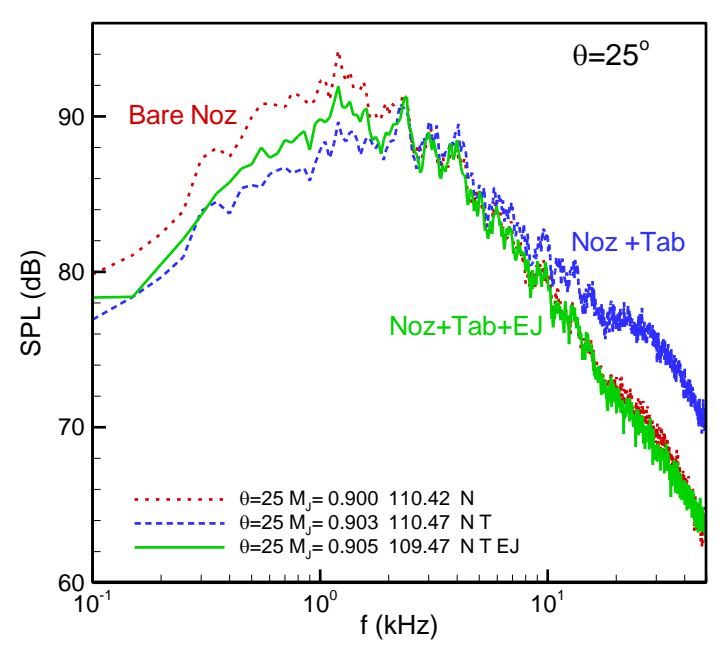
fitted with tabs without ejector, green: nozzle with tabs and ejector. The third column in legend is OASPL (dB).
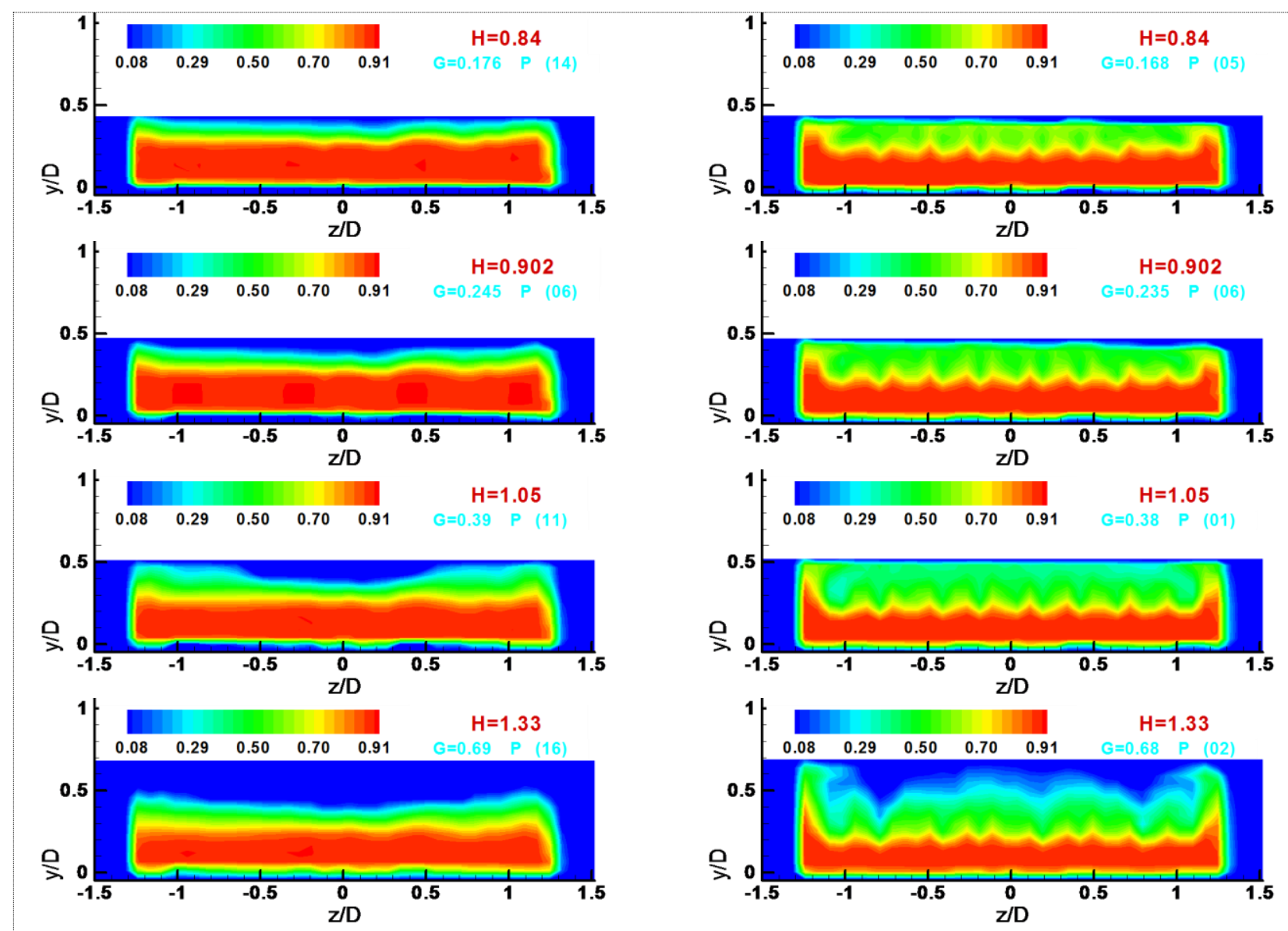

Figure 11 Continued next page. 

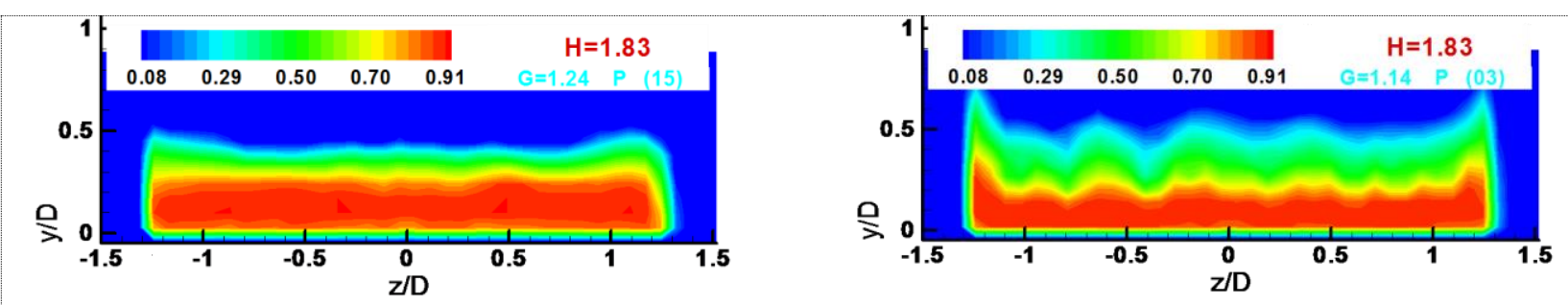

Figure 11 Mach number contours 0.04 " downstream of ejector exit for different $H$ as indicated; $M_{j}$ $=0.9$. Left column: no tab, right column: tab.
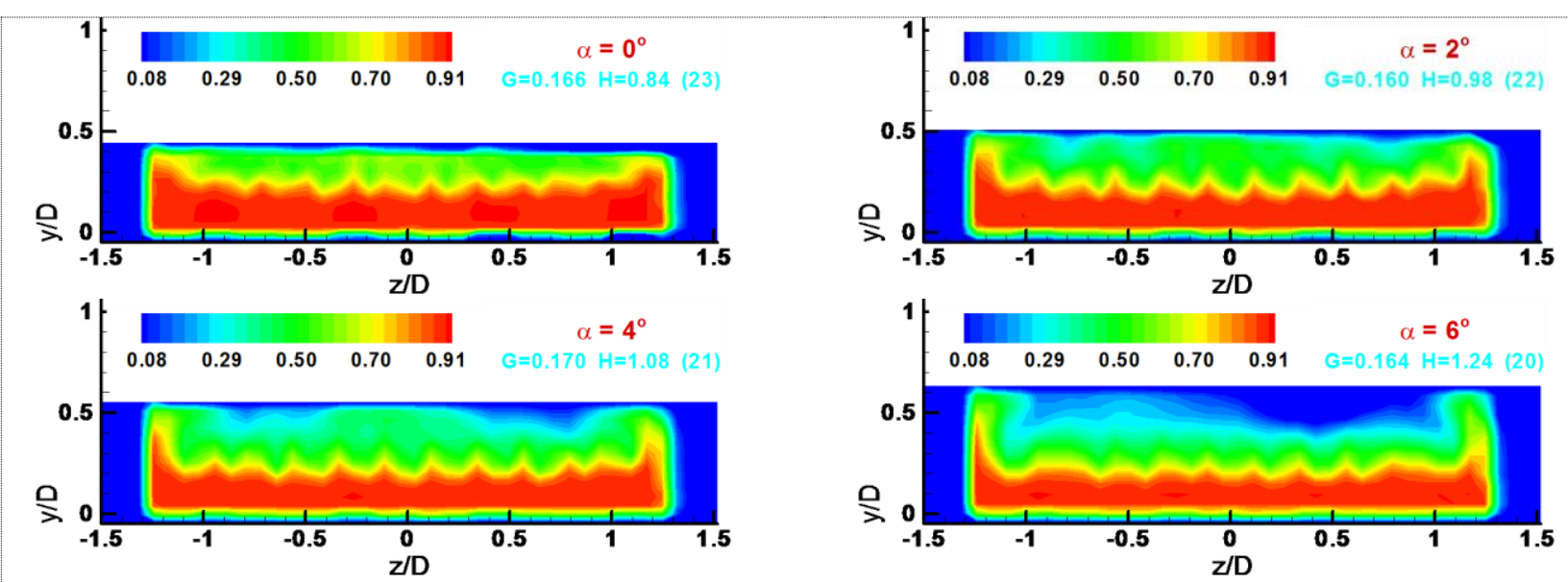

Figure 12 Mach number contours 0.04" downstream of ejector exit for different divergence $(\alpha)$ of upper plate, as indicated; $M_{j}=0.9$, tab cases.
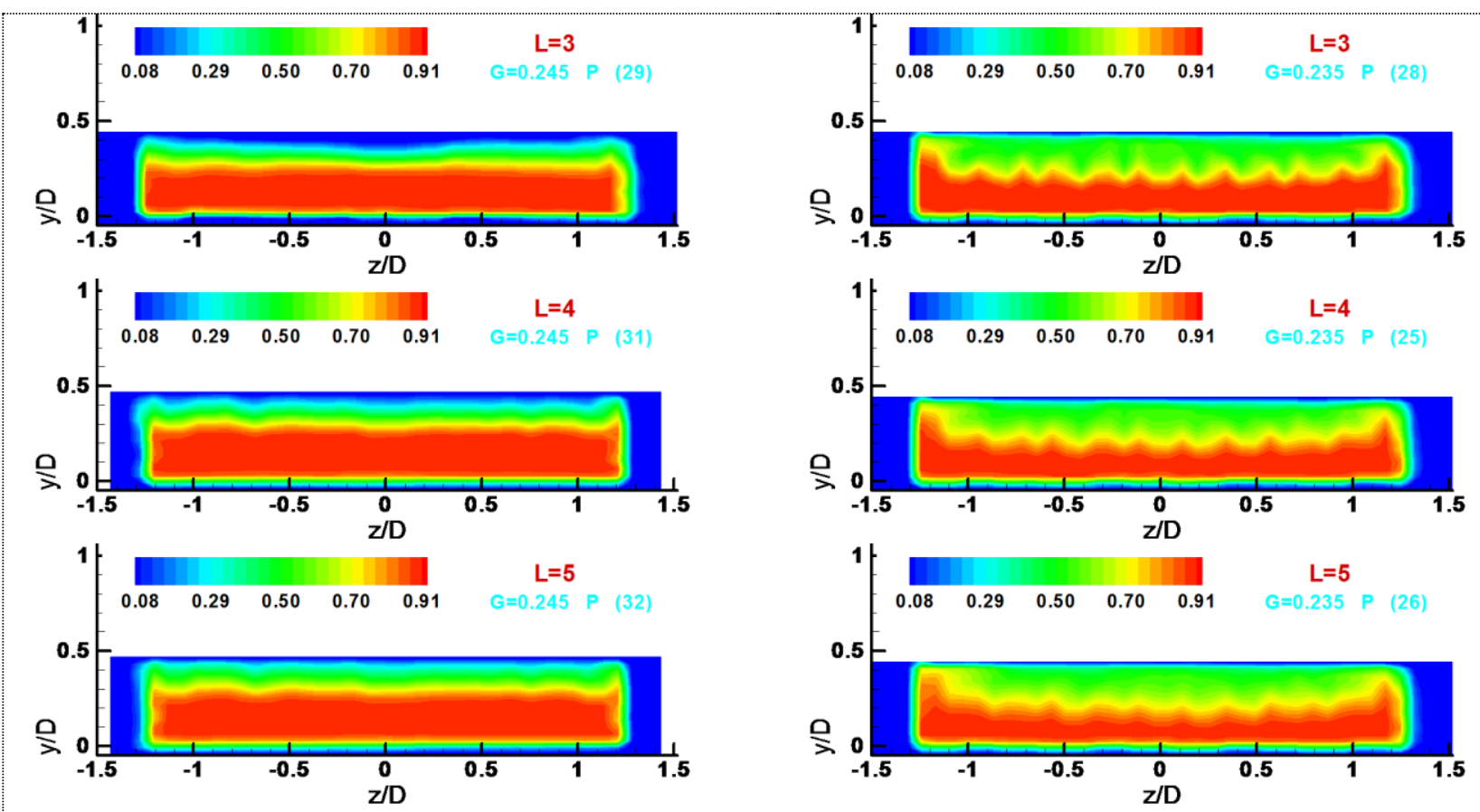

Figure 13 Continued next page. 

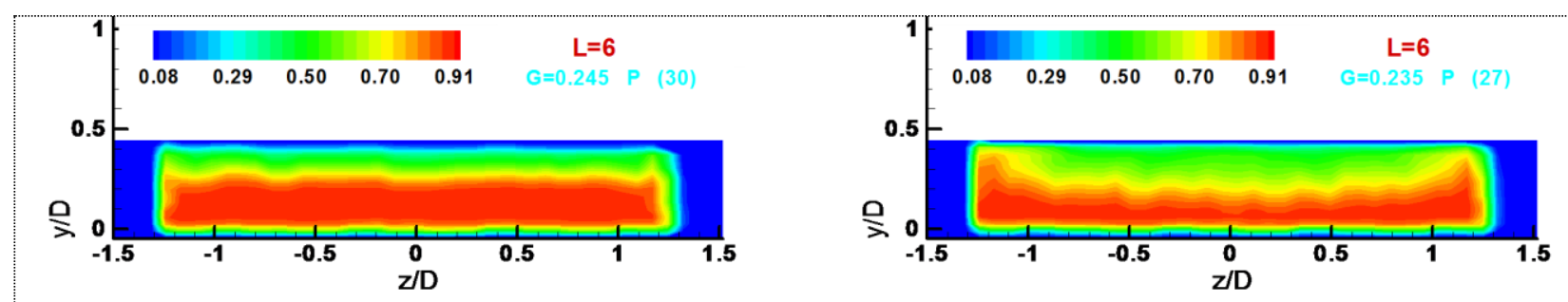

Figure 13 Mach number contours 0.22 " downstream of ejector exit for different Length, $L$, as indicated; $M_{j}=0.9$. Left column: no tab, right column: tab.

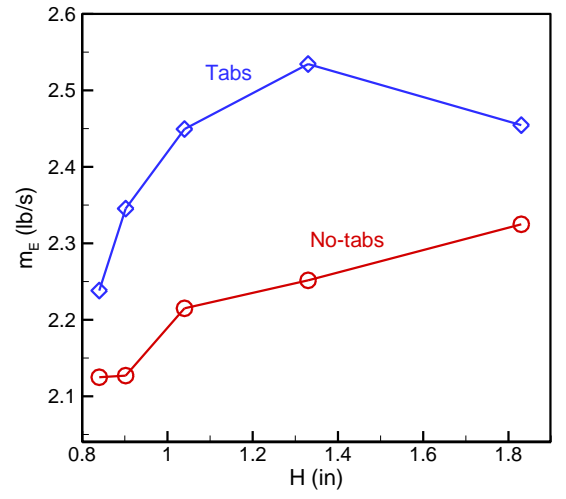

Figure 14 Mass flow rate at exit of ejector versus $H$; with and without tabs, $M_{j}=0.9$.

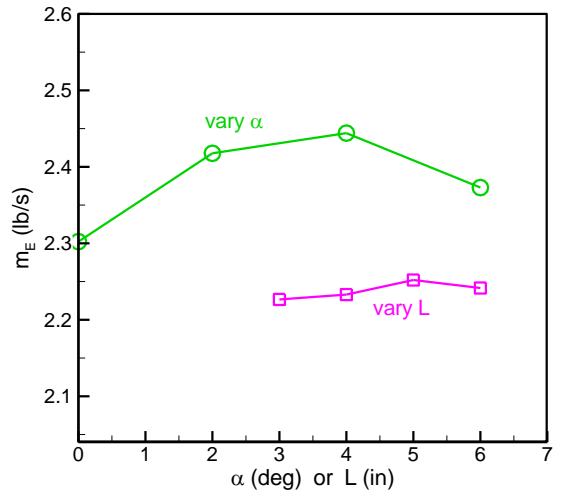

Fig. 15 Mass flow rate at exit of ejector versus $\alpha$ and $L$; all tab cases, $M_{j}=0.9$.

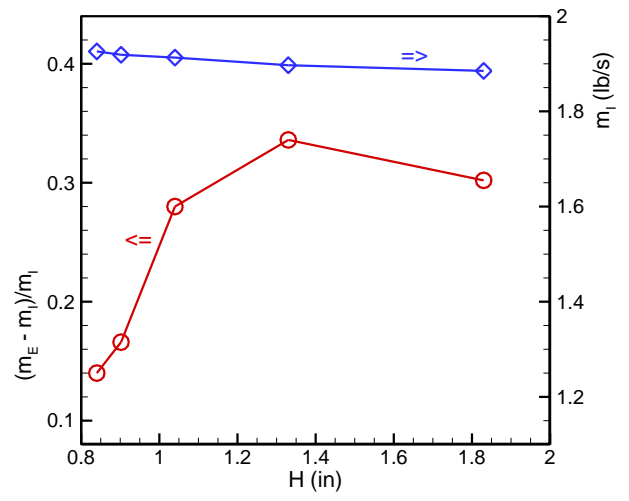

Fig. 16 Primary mass flow and entrainment versus $H ; M_{j}=0.9$, tab cases. Ordinate scales for mass flow and entrainment are on right and left, respectively, as indicated by the arrows. 